\title{
American Ginseng (Panax quinquefolium L.) as a Source of Bioactive Phytochemicals with Pro-Health Properties
}

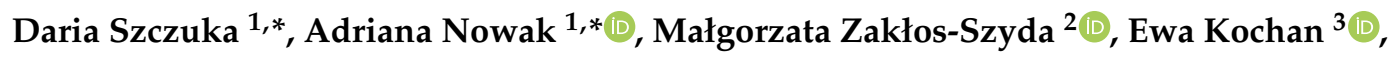 \\ Grażyna Szymańska ${ }^{3}$ (D) , Ilona Motyl ${ }^{1}$ (D) and Janusz Blasiak ${ }^{4}$ (D) \\ 1 Institute of Fermentation Technology and Microbiology, Lodz University of Technology, Wolczanska 171/173, \\ 90-924 Lodz, Poland; ilona.moty@p.lodz.pl \\ 2 Institute of Technical Biochemistry, Lodz University of Technology, Stefanowskiego 4/10, 90-924 Lodz, \\ Poland; malgorzata.zaklos-szyda@p.lodz.pl \\ 3 Pharmaceutical Biotechnology Department, Medical University of Lodz, Muszynskiego 1, 90-151 Lodz, \\ Poland; ewa.kochan@umed.lodz.pl (E.K.); grazyna.szymanska@umed.lodz.pl (G.S.) \\ 4 Department of Molecular Genetics, Faculty of Biology and Environmental Protection, University of Lodz, \\ Pomorska 141/143, 90-236 Lodz, Poland; janusz.blasiak@biol.uni.lodz.pl \\ * Correspondence: 203190@edu.p.lodz.pl (D.S.); adriana.nowak@p.lodz.pl (A.N.)
}

Received: 12 April 2019; Accepted: 7 May 2019; Published: 9 May 2019

\begin{abstract}
Panax quinquefolium L. (American Ginseng, AG) is an herb characteristic for regions of North America and Asia. Due to its beneficial properties it has been extensively investigated for decades. Nowadays, it is one of the most commonly applied medical herbs worldwide. Active compounds of AG are ginsenosides, saponins of the glycosides group that are abundant in roots, leaves, stem, and fruits of the plant. Ginsenosides are suggested to be primarily responsible for health-beneficial effects of AG. AG acts on the nervous system; it was reported to improve the cognitive function in a mouse model of Alzheimer's disease, display anxiolytic activity, and neuroprotective effects against neuronal damage resulting from ischemic stroke in animals, demonstrate anxiolytic activity, and induce neuroprotective effects against neuronal damage in ischemic stroke in animals. Administration of AG leads to inhibition of hypertrophy in heart failure by regulation of reactive oxygen species (ROS) in mice as well as depletion of cardiac contractile function in rats. It also has an anti-diabetic and anti-obesity potential as it increases insulin sensitivity and inhibits formation of adipose tissue. AG displays anti-cancer effect by induction of apoptosis of cancer cells and reducing local inflammation. It exerts antimicrobial effects against several pathogenic strains of bacteria. Therefore, AG presents a high potential to induce beneficial health effects in humans and should be further explored to formulate precise nutritional recommendations, as well as to assess its value in prevention and therapy of some disorders, including cancer.
\end{abstract}

Keywords: Panax quinquefolium L.; ginsenosides; anti-cancer activity; anti-diabetic potential; antimicrobial effect

\section{Introduction}

For centuries, phytochemicals have played a significant role in human health protection and treatment of many diseases. These plant-derived substances are reported to display anti-cancer, antimicrobial and anti-diabetic activity [1]. They were also reported to diminish the risk of several disorders such as cardiovascular and neurodegenerative diseases [2].

Panax quinquefolium L. (American Ginseng, AG) is an example of a plant rich in bioactive phytochemicals. Its active compounds-ginsenosides-have been documented to exert a wide 
range of different biological activities resulting in hypoglycemic, anti-inflammatory, cardio protective, and anti-tumor effects [3,4]. A therapeutic potential of AG in chronic obstructive pulmonary disease has been also suggested [5]. It can also act as an agent diminishing unpleasant menopause symptoms [6].

By now, reviews of AG focused mostly on its chemical analysis and ecological aspects of its use and health-related activities were mainly limited to nervous and cardiovascular systems [7-9]. Recently, some reviews addressing molecular targets in pharmacological activities of AG components were published [10-12].

The review updates information on general properties of AG and focuses on its anti-diabetic, anti-obesity, anti-cancer, anti-aging, and antimicrobial activities. Special attention is paid to the metabolism of ginsenosides by intestinal microbiota and the action of AG in nervous, cardiovascular, and gastrointestinal systems is briefly discussed.

\section{American Ginseng: Cultivation, Characteristics, and Applications}

The Panax genus plays an important role among natural compounds applied in human healthcare. Within its 11 species, the three most commonly used are Panax ginseng (Asian ginseng), Panax notoginseng and Panax quinquefolium (American Ginseng). All three species have received significant attention due to their profitable features and have been implemented in healthcare products and food additives all over the world [13-15]. North Asia countries, namely eastern regions of China, Japan, and Korea are abundant in Asian ginseng. Notoginseng is an herbal pharmaceutical of Chinese origin and is cultivated mainly in China [16,17].

AG as opposed to Asian ginseng and notoginseng is an herb characteristic for regions of North America. It inhabits areas from Quebec to Manitoba in Canada to Georgia, Louisiana, Arkansas, and Oklahoma in the United States [18]. The greatest area of AG cultivation is located in Wisconsin [19]. Since 1980s this species of ginseng is also cultivated in China [20].

AG represents perennial, forest herbs [21]. Individual leaves vary in shape from lance to oblong ones. In the summer small flowers of white colour appear. They are located on a simple umbel within the major leaf axis. The appearance of flowers is followed by berry-like red fruits that contain up to three seeds. Ginseng roots are variably branched and have fleshy white colour. Sometimes, when the plant grows older, it displays an auxiliary root that can be used as a "spare" in the event of damage of the major root [22].

AG is fertilized by generalist insects such as small Halictid bees and has a mixed-mating breeding system. Its process of reproduction is based exclusively on seeds and occurs after a pre-reproductive period that lasts about 3 years. First, green fruits appear in July and August and they accomplish maturity and redness between August and November [18]. Harvesting of roots is possible after 4 years from seeding. However, it should be underlined that cultivated roots are usually harvested after 3-4 years of growth, while wildly grown ginseng is usually harvested at the 8 th year of growth or later $[23,24]$.

Thermally processed ginseng roots can be classified into 2 types: fresh (red) and dried (white) [25]. Roots that are subjected to sun dehydration are called white ginseng. Red ginseng is the one after thermal processing with application of steam and high temperature that result in damage to enzymes that cleave active compounds [26]. This procedure stabilizes ginseng without changes in its activity, which is the same as the activity of fresh root. Such thermal processing of ginseng roots also prolongs their shelf life, so dried roots are preferable in natural Asian medicine. Both forms of AG have similar chemical compositions and pharmacological properties [27].

Ginseng medical application in Eastern Europe dates back 2000 years. However, the name of the genus, Panax (pan from Greek means "all", anox means "treat" which altogether can be understood as "treats all diseases") was given to it in the first half of the 19th century by Russian scientist Carl Meyer [28].

Varieties of products containing AG are currently available on the market, starting from powders and pellets, ending up on teas. There are roots of ginseng in a form of dried shredded slices and 
extracts of this plant. Ginseng dried flowers or flakes are also available [29]. In many countries ginseng is being implemented in hair conditioners, shower gels, lotions, and shampoos. Its roots and rhizomes are used as diet supplements, drugs, and finally as food. In the USA there are candies and drinks containing AG extract; in Korea, soups and salads containing ginseng are common, while in China ginseng extract is added to alcoholic beverages [27-30].

\section{Bioactive Phytochemicals of American Ginseng}

Bioactive compounds responsible for variety of beneficial activities of AG in humans are called ginsenosides or panaxosides. From the chemical point of view, these compounds are glycosides consisting of a non-sugar part-an aglycone and a sugar chain or chains. In the chemical structure of ginsenosides, three types of aglycones can be distinguished: tetracyclic of dammarane type, pentacyclic of oleanolic acid type and tetracyclic of the ocotillol type.

The sugar part of saponins includes hexoses (glucose, galactose), 6-deoxyhexoses (furanose, rhamnose), pentoses (arabinose, xylose) and uronic acids (glucuronic acid). They are usually in cyclic form and are linked to the aglycone by semi-acetal bonds [31,32].

Ginsenosides are designated " $R x$ ", where " $R$ " means root, and " $x$ " describes, in alphabetical order, the polarity of the compound according to their mobility on thin layer chromatography plates, from index "a" to " $h$ ". For example, the Ra metabolite is the least polar compound. Most ginsenosides consist of a dammarane skeleton with 17 carbon atoms arranged in four rings. Due to the number of hydroxyl groups these compounds can be classified into two main categories: protopanaxadiol (PPD) and protopanaxatriol (PPT) [33].

Protopanaxadiols are the dammarane-type ginsenosides with sugar moiety at C-3 and/or C-20. Their structures are also characterized by a linear linkage between glycosyl chains and acylation occurring at the 6-OH of the terminal glucose of a three-sugar chain. Within this group the Rb1, Rb2, $\mathrm{Rb} 3, \mathrm{Rc}, \mathrm{Rd}, \mathrm{Rg} 3$, and $\mathrm{Rh} 2$ can be distinguished. Over 30 ginsenosides belonging to PPD type are classified to the $\mathrm{Rb}$ group. Protopanaxatriols are dammarane-type ginsenosides and they include ginsenosides Re, Rf, Rg1, Rg2, Rh1, F1, F3 and notoginsenoside R1. However, in the PPT moiety there is a hydroxyl group at C-6 distinguishing them from PPD [34,35]. Other features of PPT structures are at most two glycosyl chains and a linear linkage of saccharide chains [34]. Ginsenosides Rb1, Re, Rd, $\operatorname{Rg} 1$ and $\mathrm{Rb} 3$ are considered as six major saponins and make up more than $70 \%$ of total ginsenoside content in AG [35].

Another constituent is oleanolic acid, which contains a pentacyclic triterpene skeleton [36]. Its derivative is ginsenoside Ro [37]. Last but not least ocotillol that has a five-membered epoxy ring at C-20 needs to be mentioned [38]. An example of ocotillol-type panaxoside isolated from the roots and leaves of AG is pseudoginsenoside F11 (p-F11) [39].

Two ginsenosides are considered as major marker compounds that could discriminate $P$. ginseng and AG. These are ginsenoside Rf, present in Asian ginseng and p-F11occurring in AG [40]. It was documented that AG is a source of unsaturated fatty acids, including linolenic acid, which is especially important as its consumption decreases frequency of chronic diseases such as arrhythmia and arthritis [41]. Furthermore, ginseng roots contain polysaccharides. They are made up of a complex chain of monosaccharides rich in L-arabinose, D-galactose, L-rhamnose, D-galacturonic acid, D-glucuronic acid and D-galactosyl residues [42]. Wang et al. isolated a novel neutral polysaccharide from the roots of AG [43]. Monosaccharide composition analysis demonstrated that it consisted of glucose and galactose in a molar ratio 1:1.15. It was observed to hinder inflammation by inhibition of inflammatory-related mediator nitric oxide (NO) and cytokines, including tumor necrosis factor (TNF), interleukin 6 (IL-6), and interleukin 1. This indicates AG potential for application in diseases linked with inflammation, including atherosclerosis [43].

Apart from saponins and polysaccharides AG contains terpenes, phenolic compounds, amino acids, flavonoids, volatile oils, vitamins, and minerals [44,45]. A study conducted by Kochan et al. indicated that the content of triterpene saponins in hairy root cultures of AG can be increased by 
application of trans-anethole as elicitator [46]. It was observed to stimulate production of 9 different ginsenosides: $\mathrm{Rb} 1, \mathrm{Rb} 2, \mathrm{Rb} 3, \mathrm{Rc}, \mathrm{Rd}, \mathrm{Rg} 1, \mathrm{Rg} 2, \mathrm{Re}$, and $\mathrm{Rf}$, among which the Re metabolite was documented with the highest rate of production, 3.9 fold in comparison to untreated root [46].

Although all ginseng plants contain either protopanaxadiols (PPD group) or protopanaxatriols (PPT group), their compositions may be different. Asian ginseng contains mainly $\mathrm{Rb} 1, \mathrm{Rb} 2$, and $\mathrm{Rg} 1$ ginsenosides [47]. Notoginseng is rich in ginsenosides $\mathrm{Rb} 1, \mathrm{Rd}, \mathrm{Rg} 1$ and notoginsenoside R1, while $\mathrm{AG}$ in ginsenosides $\mathrm{Rb} 1, \mathrm{Rd}$ and $\mathrm{Re}$ [47]. It was also observed that the same species of AG cultivated in different locations display differences in chemical composition, including content of active compounds, and because of that they display different health beneficial activities $[48,49]$. In addition, many reports confirm that with the age of ginseng plant, the content of saponins increases [23,50,51]. It is also worth mentioning, that although pharmacopoeia raw material of ginseng is root, ginsenosides also occur in other organs of ginseng plant such as: leaves, stems, fruits, and even in small amounts in the seeds $[50,52]$. Chemical structure of some AG ginsenosides, as well as their pharmacological activities are presented in Figure 1 and Table 1, respectively.
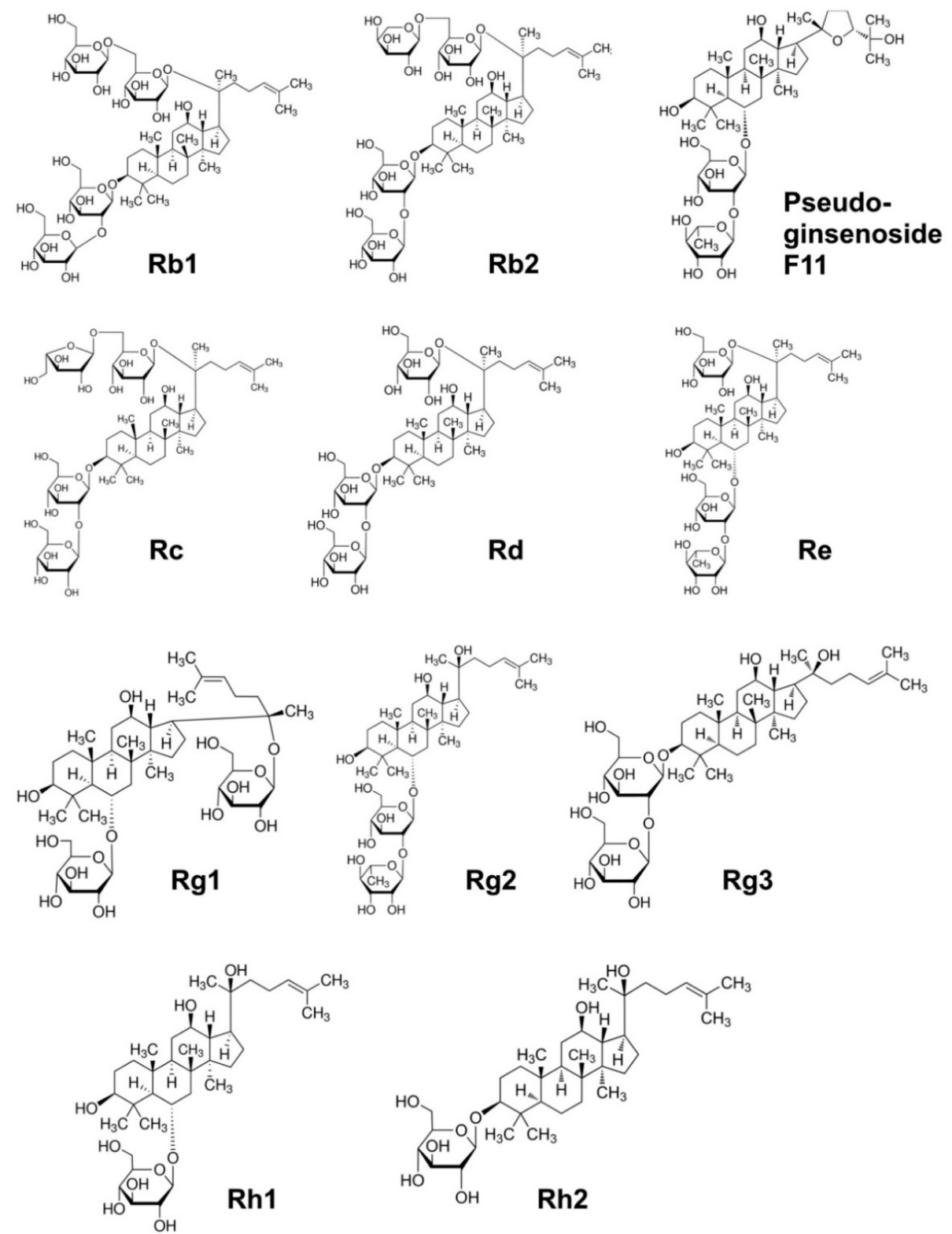

Figure 1. Chemical structure of main ginsenosides present in American Ginseng. 
Table 1. Main ginsenosides of American Ginseng and their pharmacological activity.

\begin{tabular}{|c|c|c|}
\hline Pharmacological Action & Ginsenoside & Reference \\
\hline $\begin{array}{l}\text { Positively affects memory processes; induces synthesis of acetylcholine } \\
\text { in the hippocampus by stimulating choline acetyltransferase; induces } \\
\text { apoptosis and inhibits angiogenesis in cancer cells; inhibits the release } \\
\text { of inflammatory leukotrienes; reversibly and tonically blocks } \\
\text { voltage-dependent Na+ channels in the brain reducing detrimental } \\
\text { effects of hypoxia; downregulates the COX-2 gene; stabilises } \\
\text { neutrophils and lymphocytes; inhibits the release of histamine; blocks } \\
\text { calcium channels and stabilised the heart; reduces blood sugar levels; } \\
\text { anti-diabetic, insulin-sensitising and anti-obesity actions; neurotropic, } \\
\text { neuroprotective, oestrogen-like activity; stimulates GABA receptors and } \\
\text { induces a depressive effect on brain function, which underlines its } \\
\text { calming, anxiolytic, sleeping, relaxing and antipsychotic effects }\end{array}$ & $\mathrm{Rb} 1, \mathrm{Rb} 2, \mathrm{Rc}$ & {$[9,22,53-55]$} \\
\hline $\begin{array}{l}\text { Stimulates superoxide dismutase; inhibits angiogenesis in cancer; } \\
\text { prevents diabetes; lowers cholesterol and triglycerides levels, activates } \\
\text { lipolysis; corticotropic and oestrogenic activity }\end{array}$ & $\mathrm{Rb} 2$ & {$[9,54,55]$} \\
\hline Inhibits proliferation of breast cancer cells; induces corticotropic effects & Rc & {$[9,22,54]$} \\
\hline $\begin{array}{l}\text { Promotes neurites outgrowth, an important process for neuronal repair; } \\
\text { induces corticotropic effects }\end{array}$ & Rd, Rc, Re & {$[9,22,54-57]$} \\
\hline $\begin{array}{l}\text { Scavenges hydroxyl radicals and degrades } \mathrm{H}_{2} \mathrm{O}_{2} \text {; reduces blood sugar } \\
\text { levels; induces cardioprotective effects; activates cGMP and relaxes } \\
\text { smooth muscles }\end{array}$ & $\operatorname{Re}$ & {$[9,22,54-56]$} \\
\hline $\begin{array}{l}\text { Downregulates the COX-2 gene; stabilises neutrophils and lymphocytes; } \\
\text { inhibits histamine release; inhibits platelet-induced activation of } \\
\text { thromboxane; increases insulin receptors; increases T-helper } \\
\text { lymphocytes; inhibits release of endothelin and relaxation of the smooth } \\
\text { muscle of blood vessels; activates cyclic guanosine monophosphate and } \\
\text { relaxes the smooth muscle (hypotensive effect); blocks calcium channels } \\
\text { and stabilised the heart; reduces blood sugar levels }\end{array}$ & $\operatorname{Rg} 1$ & {$[22,55,56]$} \\
\hline Inhibits neuronal acetylcholine & $\operatorname{Rg} 2$ & [22] \\
\hline $\begin{array}{l}\text { Inhibits platelet aggregation induced by thrombin; relaxes the smooth } \\
\text { muscle of the blood vessels by activating the } \mathrm{K}+\text { channels and releases } \\
\mathrm{Ca}^{2+} \text {; inhibits progression of tumours and reduces drug resistance of } \\
\text { cancer cells; inhibits endothelin and relaxation of the smooth muscle of } \\
\text { blood vessels; induces hypotensive effect; downregulates the COX-2 } \\
\text { gene; stabilises neutrophils and lymphocytes; inhibits histamine release; } \\
\text { modulates mitogen-activated protein kinases, thus inhibiting the spread } \\
\text { of cancer cells }\end{array}$ & $\operatorname{Rg} 3$ & {$[22,53,55,56,58]$} \\
\hline $\begin{array}{l}\text { Activates oestrogen receptor; inhibits proliferation of cancer cells and } \\
\text { induces apoptosis }\end{array}$ & Rh1 & {$[22,58]$} \\
\hline Inhibits breast, liver and prostate cancer cells proliferation & $\mathrm{Rh} 2$ & {$[22,58]$} \\
\hline Assists memory improvement; induces neuroprotective effects & $\begin{array}{c}\text { Pseudoginse-n } \\
\text { F11 }\end{array}$ & [22] \\
\hline
\end{tabular}

\section{Pro-Health Effects of American Ginseng}

Influence of ginsenosides on human health has been extensively investigated over decades. Currently, it is one of the most commonly applied medical herbs all over the world [52]. AG exerts profitable effects on the functions of nervous, cardiovascular, and immune system [59-61]. Furthermore, variety of research showed activity of ginsenosides as anti-cancer and antimicrobial agents [62,63]. AG is considered an Adaptogen, a substance that enhances human health by restoration of homeostasis [10]. The main health beneficial activities of AG are presented in Figure 2. 


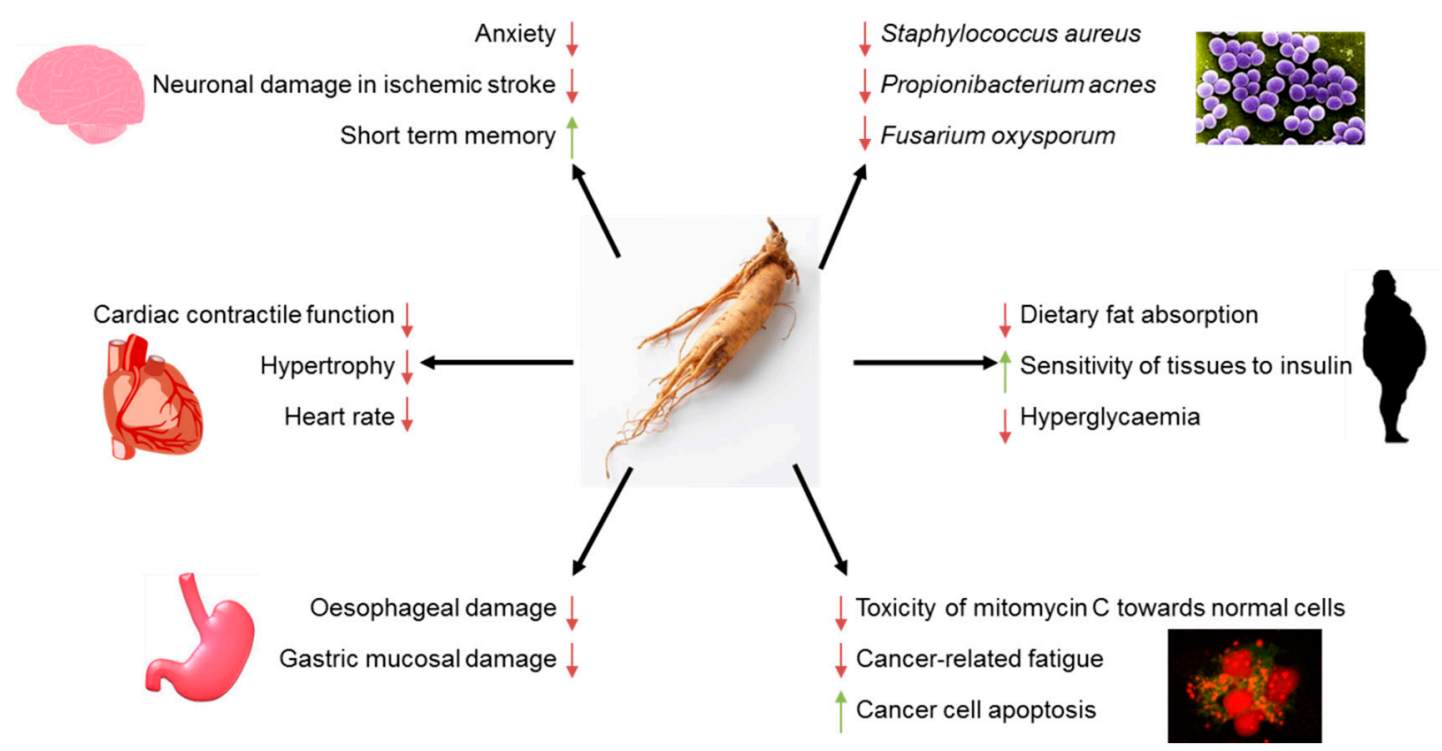

Figure 2. The main health beneficial activities of American Ginseng. It mitigates symptoms typical for Alzheimer disease, prevents neuronal damage in the course of ischaemic stroke and enhances cognitive performance-predominantly short-term memory. It depresses cardiac contractile function, decreases heart rate and diminishes hypertrophy. Furthermore, it attenuates oesophageal damage resulted from reflux oesophagitis and prevents the gastric mucosa from ulcer formation. It displays antimicrobial activity against different pathogenic strains. Its anti-obesity effect is mediated by lowering of dietary fat absorption. Moreover, it has anti-diabetes potential manifested by improvement of tissues' sensitivity towards insulin. Last, but not least, it exerts anti-cancer effects; its administration leads to apoptosis of cancer cells, helps to eliminate toxic effects of chemotherapeutics to healthy cells, and decreases cancer-related fatigue.

\subsection{Nervous System}

Shin et al. observed that AG improved the status of mice with a model of Alzheimer-like syndromes [64]. In Alzheimer's disease, amyloid-beta (A $\beta$ ) peptides promote damage of presynaptic cholinergic system and decrease in choline acetyltransferase (ChAT) activity. After application of AG extract (30-300 mg/kg bw), an increase of acetylcholine (AChE) production resulted from choline-acetyltransferase up-regulation in the brain of mice with $\beta$-amyloid was observed. Consequently, learning and memory functions were improved [64].

According to a general population-based survey, almost $33.7 \%$ of the world population is afflicted by an anxiety disorder at some point during their lifetime [65]. Wei et al. observed an anxiolytic effect of AG ginsenosides (50 and $100 \mathrm{mg} / \mathrm{kg} \mathrm{bw}$ ) in mice and compared it with that induced by diazepam [66]. AG saponins in contrary to diazepam did not influence locomotion abilities [66]. Furthermore, AG was shown to enhance cognitive performance in volunteers predominantly by improving working memory processes (200 mg dose) [67]. Liu et al. observed a neuroprotective effect of AG in the tsA-201 embryonic kidney cells transfected with cDNA expressing $\alpha$ subunits of the $\mathrm{Brain}_{2 \mathrm{a}} \mathrm{Na}^{+}$channel in ischemia [68]. Abnormal $\mathrm{Na}(+)$ flux in ischemia results in neuronal damage and AG extract $(1$ and $3 \mathrm{mg} / \mathrm{mL}$ dosages) reversibly blocked the channel in a dose-dependent manner. Ginsenoside Rg1, an active compound of AG as well as its primary and end metabolites Rh1 and protopanaxatriol (5-10 mg/kg bw), respectively, significantly diminished memory impairment in mice and increased hippocampal excitability of anaesthetized rats [69].

AG $(10 \mathrm{mg} / \mathrm{kg}$ bw administered 4 times in a $2 \mathrm{~h}$ interval and in a dosage of 4 and $8 \mathrm{mg} / \mathrm{kg}$ bw twice in a $4 \mathrm{~h}$ interval) mitigated anxiety caused by methamphetamine administration in rats, shortened time of immobility in forced swimming test, and significantly decreased the number of errors in the maze test [70]. Results of some studies on AG activity in the nervous system are presented in Table 2. 
Table 2. Effects of American Ginseng in the nervous system.

\begin{tabular}{|c|c|}
\hline Effect & Reference \\
\hline $\begin{array}{l}\text { Mitigation of symptoms of Alzheimer disease in mice by } \\
\text { AChE-acetyltransferase upregulation }\end{array}$ & {$[64]$} \\
\hline Anxiolytic effect without influence on locomotion abilities in mice & [66] \\
\hline $\begin{array}{c}\text { Improvement of cognitive performance, predominantly working memory and calmness in } \\
\text { young adults }\end{array}$ & [67] \\
\hline $\begin{array}{l}\text { Neuroprotective effect on tsA-201 cells transfected with cDNA expressing } \alpha \text { subunits of the } \\
\qquad \text { Brain }_{2 \mathrm{a}} \mathrm{Na}^{+} \text {channel during ischaemia by blocking } \mathrm{Na}^{+} \text {channel }\end{array}$ & [68] \\
\hline $\begin{array}{l}\text { Rg1 mitigation of memory impairment in mice and increase of hippocampal excitability in } \\
\text { anaesthetised rats }\end{array}$ & [69] \\
\hline Mitigation of anxiety caused by methamphetamine abuse in rats & [70] \\
\hline $\begin{array}{l}\text { Decrease of iNOS synthase and demyelination scores in the central nervous system in mice } \\
\text { with experimental autoimmune encephalomyelitis }\end{array}$ & [71] \\
\hline Protection against scopolamine-induced memory deficits in rats & [72] \\
\hline $\begin{array}{l}\text { Neuroprotection of pseudoginsenoside F11 on 6-hydroxydopamine-induced Parkinson's } \\
\text { disease in rats }\end{array}$ & [73] \\
\hline $\begin{array}{l}\text { Inhibition of neuronal apoptosis and decrease of neurite damage via regulation of } \\
\text { endoplasmic reticulum stress after acute spinal cord injury in rats }\end{array}$ & [74] \\
\hline $\begin{array}{l}\text { F11 inhibition of hyper locomotion and increase of extracellular dopamine release by } \\
\text { GABAergic neurons and } \mu \text {-opioid receptors regulation in mice }\end{array}$ & [75] \\
\hline $\begin{array}{l}\text { Modulation of brain function by inhibition of neuronal discharge frequency in brainstem } \\
\text { unitary activity in rats }\end{array}$ & [76] \\
\hline Neuroprotection on anxiety-like behaviour induced by sleep deprivation in mice & [77] \\
\hline
\end{tabular}

\subsection{Cardiovascular and Gastrointestinal Systems}

Jiang et al. observed structural changes and cardiac function attenuation with no changes in blood pressure in hypertensive rats after administration of ginsenosides $\mathrm{Rb} 1$ and $\mathrm{Rg} 3$ ( $20 \mathrm{mg} / \mathrm{kg} \mathrm{bw}$ ) [78]. In another study, Jiang et al. observed that a single dose ( $300 \mathrm{mg} / \mathrm{kg} \mathrm{bw})$ of AG extract depressed the cardiac contractile function in rats, resulting in a reduced heart rate maintained for $24 \mathrm{~h} \mathrm{[79].}$

Ischemia and hypoxia associated with stroke result in cytokines release, glutamate excitotoxicity (nerve cells damage and death due to excessive stimulation by glutamate), oxidative stress, nerve cells apoptosis, invalid metabolism and inflammation [80]. Pre-treatment with P. quinquefolium PPD saponins dosage of $(25$ and $50 \mathrm{mg} / \mathrm{kg} \mathrm{bw})$ significantly increased the activities of ROS-regulating enzymes in the brain tissue of rats. These results indicate that because of its antioxidant properties, Panax extract might act protectively against stroke [80]. Administration of AG extract to rats inhibited hypertrophy and heart failure induced by isoproterenol through attenuation of cardiac adrenergic responses [81]. AG (50 mg/kg bw for 7 days) displayed a preventive effect against cardiomyopathy in mice, which was underlined by inhibition of oxidative stress [82]. It also protected mouse hearts from reperfusion injury through upregulation of inducible nitric oxide synthase (iNOS) expression [82].

Aqueous extract of AG inhibited superoxide generation in the heart of mice challenged with lipopolysaccharide to induce endotoxemia, a model of sepsis [83]. A similar effect was observed in cultured cardiomyocytes. Moreover, the extract inhibited the expression of NOX2, a main cardiac isoform of NADPH oxidase, a major enzyme producing ROS. It was concluded that AG inhibited the myocardial NOX2-ERK1/2-TNF- $\alpha$ signalling pathway. Antioxidant action of AG in cardiomyocytes was associated with the activation of nuclear factor (erythroid-derived 2)-like 2 (Nrf2) [4].

AG extract (50, 100, and $200 \mathrm{mg} / \mathrm{kg} \mathrm{bw}$ ) protected against oesophageal damage resulted from reflux oesophagitis through reduction of inflammatory cells and oxidative load in the oesophagus [84]. 
Another study demonstrated that AG (500 and $1250 \mathrm{mg} / \mathrm{kg}$ bw) protected rats from gastric mucosa damage induced by a chronic ethanol intake [85].

\subsection{Anti-Cancer Activity}

Cancer is one of the most common terminal diseases and is considered the second leading cause of death globally. According to World Health Organization it was estimated to account for 9.6 million deaths in 2018 [86]. Application of phytochemicals in cancer prevention and therapy is an emerging issue due to their availability and lack of adverse side effects [87-91]. AG has also been investigated in terms of its anti-cancer activity. Many studies on anti-cancer activity of AG focus on colorectal cancer. It represents approximately $19 \%$ of cancer incidence worldwide and accounted for 860,000 deaths in 2018 [86]. One of the most abundant AG constituents, ginsenoside Rh2, exerted a strong anti-tumor effect on colorectal cancer HCT116 cell line [92]. Ginsenoside Rh2 decreased proliferation of HCT116 cells through inhibition of PDZ-binding kinase/T-LAK cell-originated protein kinase, which is a serine/threonine protein kinase highly expressed in these cells [92]. HCT116 and HT-29 colorectal cancer cells were arrested in G1 phase of the cell cycle after incubation with the compound K, a gut microbiota metabolite of ginsenoside Rb1 [93]. Similar results were obtained by Gao et al. who showed that PPD inhibited HCT116 cancer cells proliferation through G1/S checkpoint arrest [94]. PPD inhibited tumor growth in xenograft HCT116 mice through the inhibition of the nuclear factor kappa-light-chain-enhancer of activated B cells (NF-kB) and c-Jun N-terminal kinase (JNK) signaling pathways [94]. AG inhibited formation of colitis in mice induced by azoxymethane/dextran sodium sulphate during and after exposure to the carcinogens along with reduction of activation of pro-inflammatory cytokines [95].

Water extract of AG $(20,40,60$, and $80 \mathrm{mg} / \mathrm{mL})$ changed morphological and mechanical properties of human hepatocellular carcinoma SMMC-7721 cells that displayed an increased susceptibility to apoptosis [96]. AG was also found to display anti-cancer activity in human breast cancer MCF-7 cells through inhibition of their proliferation underlined by alterations in the mitogen-activated protein kinase (MAPK) signalling pathway [97].

A $4 \mathrm{hr}$-steamed AG root extract $(\mathrm{S} 4 \mathrm{~h})(0.1 \mathrm{mg} / \mathrm{mL})$ was reported to damage mitochondria, increase ROS level, and induce apoptosis in colorectal cancer cells [98]. S4h activated the NF- $\mathrm{kB}$ pathway, which was abandoned by the removal of ROS by antioxidants. Inhibition of the NF-kB pathway by a specific inhibitor increased the extent of S4h-induced apoptosis and a similar effect was observed when antioxidants were added. Both ROS levels and apoptosis were decreased when mitochondria were protected by ROS/NF-kB-mediated survival pathway. The final conclusion from that study was that ginseng induces apoptosis in colorectal cancer cells through mitochondrial damage, which may also activate the ROS/NF-KB-mediated survival pathway.

Mitomycin C (MMC) is an antibiotic commonly applied as anti-cancer drug. Its activation leads to ROS generation, DNA alkylation, and formation of DNA interstrand crosslinks, as well as some chromosomal abbreviations [99]. Serious side effects of MMC greatly limit its use. Pawar et al. observed that AG root extract ( 50 and $100 \mathrm{mg} / \mathrm{kg}$ bw administered for 3 and 7 days) decreased the number of micronucleated polychromatic erythrocytes in mice pre-treated with MMC [100].

Cis-diamminedichloroplatinum (cisplatin) is a commonly used anti-cancer drug with nephrotoxicity as its main side effect [101]. Ma et al. showed that AG berry extract (AGBE) (300 mg/kg bw) decreased histopathological changes as well as increased levels of urea nitrogen and creatinine in serum of mice receiving cisplatin [102]. Pre-treatment with AGBE ameliorated oxidative stress induced by cisplatin. This was evidenced by a decrease in kidney malondialdehyde concentration, cytochrome P450 E1 (CYP2E1), renal 4-hydroxynonenal (4-HNE), and an increase in reduced glutathione and superoxide dismutase (SOD) content. Moreover, AGBE inhibited expression of TNF- $\alpha$, interleukin-1 $\beta$ (IL-1 $\beta$ ), cyxlooxygenase-2 (COX-2) and iNOS, proteins involved in the inflammatory response. Furthermore, pre-treatment with AGBE inhibited NF- $\mathrm{kB}$ and MAPK activated by cisplatin. Also, AGBE decreased the level of the apoptotic protein Bax, cleaved caspase 3 and 
cytochrome c released from mitochondria, but increased the level of anti-apoptotic Bcl-2. Therefore, renal oxidative stress, inflammation and apoptosis could be involved in cisplatin-related nephrotoxicity. The authors concluded that the protective effect of AGBE against nephrotoxicity induced by cisplatin was underlined by the ROS-mediated the NF- $\mathrm{KB}$ and MAPK signaling pathways. The potential of AGBE to ameliorate side effects of cisplatin was shown earlier by Mehendale et al. who also pointed at antioxidant ginsenoside Re as an AGBE component, which could be primarily responsible for the observed effects [103].

Ionizing radiation (IR) damages cells by a direct or indirect effect. The former results from absorption of a quantum of IR in the target site, leading to its ionization, whereas the latter is associated with water hydrolysis (radiolysis) and production of ROS, which damages biomolecules including DNA [104]. AG extract protected human lymphocytes irradiated with 1 or 2 Gy gamma irradiation in a dose-dependent manner $[105,106]$. This protective effect was manifested by a reduction in the number of micronuclei, a decrease in ROS levels, and an increase in total antioxidant capacity. The effects induced by ginseng were similar to those evoked by WR-1065, a biologically active amino thiol form of amifostine (WR-2721), the gold standard of chemical radio protectors. It is worth noting that this protective effect was observed at $90 \mathrm{~min}$ after irradiation. Therefore, ginseng can be considered not only as a preventive substance in radiological protection, but also as therapeutics in post-radiation disorders. It seems that the activation of NF- $\mathrm{KB}$ may be critical for this effect as it can interact with the JNK pathway to upregulate the pro-apoptotic Fas ligand. In their earlier work, these authors showed a key role of the mitochondrial pathway in AG cytotoxicity in colorectal cancer cells as many genes of that pathway were involved in apoptosis of SW-480 colon cancer cells [107].

One of the most unwanted symptoms related to cancer and cancer therapy is cancer-related fatigue (CRF). It is defined as a relentless, subjective feeling of tiredness not related to activity that affects normal functioning [108]. It was documented to occur among patients during treatment and in patients that already completed the therapy [109]. It was shown that application of AG resulted in a decrease of CRF and a more pronounced effect was observed in patients during active cancer treatment than those who had completed therapy [110]. Some preclinical data may partly explain observed effects as AG downregulated inflammatory pathways, decreased inflammation and modulated cortisol levels in experimental animals and cell cultures, and these effects can be related to CRF [97,111-113].

\subsection{Anti-Diabetic Activity}

Abnormalities in the regulation of glucose metabolism in type 2 diabetes mellitus (T2DM) subjects lead to postprandial chronic hyperglycemia. After meal intake, glucose is released to the blood due to the activity of carbohydrate or oligosaccharide digestive enzymes, such as $\alpha$-amylase and $\alpha$-glucosidase. Systemic studies performed by Kan et al. showed that in cell-free assays AG root extract had no inhibitory activity on $\alpha$-glucosidase and $\alpha$-amylase [114]. In the same study these authors showed in vitro that AG increased glucose uptake and insulin sensitivity in differentiated adipocytes, which in turn may affect the hypoglycemic effect (Figure 3). Further research carried out on Sprague Dawley rats presented that mixture of AG root, Morus alba leaf and Trigonella foenum graecum seed preparations elevated glucose uptake and insulin sensitivity in mice 3T3-L1 adipocytes via an increase of the expression of glucose transporter 4 (GLUT4). GLUT4 transports glucose across the plasma membrane and its activity is regulated by insulin. Furthermore, accumulating data indicate that oxidative stress resulted from excessive ROS production or/and reduced antioxidant defense is involved in the pathogenesis of chronic blood glucose increase and insulin resistance. It was observed that chronic ginseng consumption by old (22 months) rats decreased the levels of ROS in heart, soleus muscle, and deep portion of the vastus lateralis muscle [115]. These animals also showed a higher activity of glutathione peroxidase (GPx) and decreased level of carbonyl group. It was concluded that ginseng consumption might ameliorate oxidant production and oxidative damage to proteins mainly by the increase in the activity of antioxidant enzymes. Ginseng in general is known to reduce blood glucose levels [116]. Yoo et al. showed that in diabetic $\mathrm{db} / \mathrm{db}$ mice treated for 30 days with a steamed 
AG roots preparation at $150 \mathrm{mg} / \mathrm{kg}$ bw the hepatic glycogen and plasma insulin levels were significantly elevated, while blood glucose was lowered [117]. Comparing to untreated, steamed AG preparation possessed higher antioxidant activities due to the increased level of ferulic and cinnamic acids and elevate liver SOD and GPx. That observation is in line with the earlier report showing that AGBE and ginsenoside Re reduced oxidative damage in MIN-6 pancreatic $\beta$-cell line induced by acute or chronic incubation with hydrogen peroxide [118]. It was concluded that the anti-diabetic effect of AGBE could be attributed to its antioxidant properties and the Re ginsenoside might significantly contribute to that effect. Furthermore, steamed ginseng preparation considerably increased high density lipoprotein (HDL) concentrations, while levels of plasma cholesterol and low density lipoprotein (LDL) were significantly decreased [119].

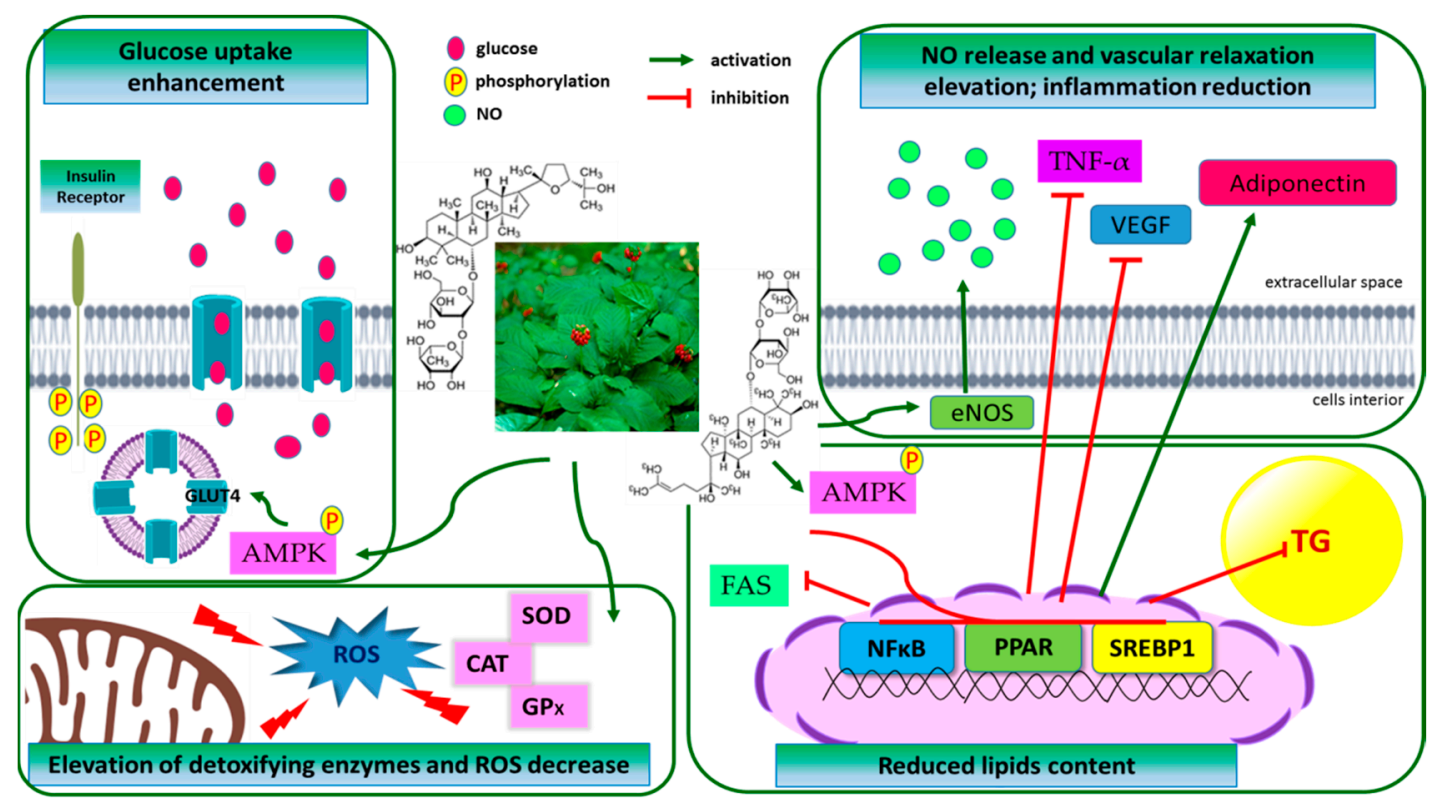

Figure 3. Proposed molecular mechanisms of anti-diabetic and anti-obesity actions of American Ginseng. See main text for more details. AMPK-AMP-activated protein kinase; CAT-catalase; eNOS — endothelial nitric oxide synthase; FAS—fatty acid synthase; GLUT4-glucose transporter 4; GPx-glutathione peroxidase; NF- $\mathrm{kB}$-nuclear factor $\mathrm{\kappa B}$; NO—nitric oxide; PPAR-peroxisome proliferator-activated receptor; ROS-reactive oxygen species; SOD-superoxide dismutase; SREBP-1c — sterol regulatory element binding protein 1c; TG-triglyceride; $\mathrm{TNF} \alpha$-tumour necrosis factor $\alpha$ and VEGF-vascular endothelial growth factor.

Most studies on the beneficial properties of ginseng are performed on extract from its root. Also, ginseng herbal supplements usually contain extract from the root. However, it was reported that different ginseng parts contain different chemical compounds with a potentially different biological activity [119]. AGBE presents different chemical content than AG root extract and this difference also concerns distinct ginsenoside compositions [120]. Shao et al. showed that AGBE directly scavenged hydrogen peroxide and superoxide anions [121]. They also showed that AGBE $(0.1,0.5$ and $1 \mathrm{mg} / \mathrm{mL})$ displayed a protective effect against acute oxidative stress induced by hydrogen peroxide and antimycin A (an inhibitor of mitochondrial complex III of the mitochondrial electron transport chain) in cultured chick cardiomyocytes. This was extended by showing that Re, the main ginsenoside of AGBE, produced essentially the same effect [122]. Therefore, both extracellular and intracellular oxidative stresses were tested and both were inhibited by AGBE. These results were supported by a subsequent work of these authors, which showed the protective effects of AGBE against chronic oxidative stress induced by hydrogen peroxide [123]. The authors concluded that this effect was associated with upregulation of peroxide detoxifying mechanisms, including catalase activity. 
Accumulating data confirm that diabetic blood glucose fluctuations strongly influence the development of cardiovascular complications via induction of endothelial cells dysfunction and apoptosis [124]. It was already shown that AG, apart from the direct scavenging of radicals, could be involved in endothelium-dependent release of $\mathrm{NO}$ and its inactivation [123]. It is known that increased quantities of ROS react directly with $\mathrm{NO}$ and produce cytotoxic peroxynitrite. Studies performed by Wang and al. demonstrated a lowered production of serum NO, ET-1 (endothelin-1), TNF- $\alpha$ and sICAM-1 (soluble intercellular adhesion molecule 1) in rats with streptozotocin-induced diabetes on high fat and high caloric diet treatment with ginseng stem and leaf saponins for 10 weeks (30-60 mg/kg bw) [124]. The authors showed that AG had comparable efficiency to metformin, a known anti-diabetic medicine, in vessel stress relief and inflammatory reaction reduction. Sen et al. observed a beneficial effect of alcoholic extract of AG on diabetic complications in mouse models of type 1 (C57BL/6 mice with streptozotocin-induced diabetes) and type 2 diabetes mellitus ( $\mathrm{db} / \mathrm{db})$ [125]. The $\mathrm{Rb} 1$ and Re ginsenosides dominated in this extract. Authors observed that ginseng administration improved dysmetabolic state in diabetes animals. Ginseng prevented oxidative stress assessed by the accumulation of superoxide anion and mRNA expression of the heme oxygenase 1 (HO-1) gene, and upregulated proteins involved in vessels architecture in the heart and the retina of diabetic mice. Cardiac functions were improved in animals receiving ginseng. The authors attributed this beneficial influence of ginseng on diabetic complications to its antioxidant, and to a lesser degree to its antihyperglycemic action.

Advanced studies performed on T2DM patients with concomitant hypertension showed that AG root preparation ( $3 \mathrm{~g} /$ day) after 3-month supplementation improved arterial stiffness and systolic blood pressure [126]. Aside from that observation, it was shown that the root preparation had no influence on blood pressure in healthy subjects. According to Xu et al., observed vasodilatory effect may be a consequence of increased NO generation after AG treatment [127]. Glucose-induced oxidative stress and damage in human umbilical vein endothelial cells (HUVECs) were prevented by incubation with ginseng root, resulting in lowering of NF- $\mathrm{kB}$, fibronectin and vascular endothelial growth factor (VEGF) mRNA and protein levels [128]. In hyperglycaemic conditions, overproduction of fibronectin decreases motility of cells and their replication; elevation of VEGF leads to endothelial dysfunction due to the enhancement of capillary formation and cell permeabilization, while the NF- $\kappa B$ activation in turn exaggerates the expression of extracellular proteins, like fibronectin and vasoactive factors (i.e., VEGF). Moreover, AG preparation acted preventive against glucose-induced oxidative DNA.

In vivo research performed by Amin et al. on rats with streptozotocin-induced diabetes showed that animal treatment with AG (at $300 \mathrm{mg} / \mathrm{kg}$ bw for 10 days) resulted in increased levels of $\beta$-cells insulin and C-peptide secreted by pancreas [129]. Their studies presented more detailed mechanism of AG anti-diabetic activity with the involvement of hepatic gluconeogenic glucose-6-phosphatase (G6Pase) and glycogenolytic liver glycogen phosphorylase inhibition.

Because AG has been used as an alternative medicine for a long time to support its clinical efficacy in glycemic control a few randomized controlled trials were performed. Vuksan et al. were the first that assessed short-term effect of AG root on postprandial glycaemia in human nondiabetic subjects and subjects with T2DM [130,131]. It was revealed that $3 \mathrm{~g}$ of root ginseng preparation administered together with the glucose challenge ( $25 \mathrm{~g}$ ) attenuated postprandial glycaemia by $20 \%$ in both, healthy and diabetic subjects, in a comparable way. However, preparation given $40 \mathrm{~min}$ prior to glucose challenge lowered glucose concentration only in diabetic patients. Further studies performed on healthy subjects treated with $3 \mathrm{~g}$ of root alcohol extract revealed no influence of preparation on postprandial glycaemia and insulin level [132]. On the other hand, the authors observed that 50\% extract possessed insulin-sensitizing effects in nondiabetic humans, improving their metabolic parameters. What is more important, advanced clinical studies performed for 12 weeks on T2DM patients with root extract at a dose of $3 \mathrm{~g} /$ day pointed its safety against liver, kidneys and hemostatic functions damage [133]. Recently, the clinical trial coordinated by Vuksan et al. demonstrated that patients dosed with $3 \mathrm{~g}$ of root preparation/day after 4-week treatment displayed significantly reduced levels of glycated 
hemoglobin $\mathrm{HbA} 1 \mathrm{c}$ (by $\geq 0.3 \%$ ), fasting blood glucose $(0.71 \mathrm{mmol} / \mathrm{L})$ and systolic blood pressure (by $5.6 \pm 2.7 \mathrm{mmHg}$ ), although the insulin release was increased by 1.5 fold. The elevation of NOx production $(1.85 \pm 2.13 \%)$ reflected ginsenosides stimulated improvement of endothelial function [134]. These outcomes are followed by present research, where different combinations of AG and other potent hypoglycemic preparation - konjac-based fiber blend (KGB) - were used as ingredients of formulas for future medicines [135]. The synergic effect of mixture (6 $\mathrm{g}$ of fibre from KGB: $3 \mathrm{~g}$ of AG per day) was obtained with clinically significant reduction in glycated hemoglobin $\mathrm{HbA} 1 \mathrm{c}(0.31 \%)$ and lipids concentrations $(8.3 \pm 3.1 \%$ in cholesterol carried within low-density lipoprotein particles (LDL-C), $7.5 \pm 2.4 \%$ in non-HDL cholesterol (non-HDL-C), $5.7 \pm 1.9 \%$ in total cholesterol (total-C) $4.1 \pm 2.1 \%$ in total-C:HDL-C ratio) over 12-week treatment of T2DM patients.

\subsection{Prevention of Obesity}

Low physical activity and elevated energy intake lead to excessive fat accumulation in the body (especially in adipose tissue) and weight gain. Obesity increases the risk of T2DM, cardiovascular complications, and certain types of cancer [136]. Whereas hypoglycemic activity of AG is quite wellknown, few studies address its anti-obesity properties. Therefore, the effect of AG on the regulation of lipid metabolism is still not fully understood (Figure 3).

Intestine absorption of dietary fat, and finally reduction of weight and hyperlipidemia, could be lowered by inhibition of pancreatic lipase activity during digestion. That enzyme is responsible for the hydrolysis of majority of dietary fats. It was shown that crude saponins isolated from AG stem and leaves acted as lipase inhibitors lowering the rate of oleic acid release from triolein [137]. The Rc, $\mathrm{Rb} 1$ and $\mathrm{Rb} 2$ ginsenosides were identified to be mainly responsible for observed effects. The same saponins extract at dosage of $1 \mathrm{~g} / \mathrm{kg}$ bw prevented the plasma triacylglycerol elevations in rats after oral intake of lipid emulsion and prevented high-fat diet-induced fat storage in adipose tissue. More recently, Liu and co-workers found that PPD types of saponins isolated from AG leaves inhibited the porcine pancreatic lipase activity in vitro in a dose-dependent manner $(0.25-1 \mathrm{mg} / \mathrm{mL})$, whereas PPT showed no inhibitory activity [138]. Furthermore, mice fed with high-fat diets containing 0.02 or $0.05 \%$ PPD had lower adipose tissue weights, limited accumulation of hepatic triacylglycerol and total cholesterol levels.

Increased number of preadipocytes (hyperplasia) and the increased size of adipocytes (hypertrophy) are the main metabolic by-products of adipose tissue modelling. As cytokines and adipokines are released from adipose tissue, adipogenesis (preadipocyte differentiation) plays a key role in obesity development [139]. Studies performed with mice preadipocyte 3T3L1 cells showed that AG ethanol extract containing $\mathrm{Rg} 1, \mathrm{Re}, \mathrm{Rb} 1, \mathrm{Rc}, \mathrm{Rb} 2$, and $\mathrm{Rd}$ ginsenosides exerted a dose-dependent effect on cells proliferation ( $\mathrm{LC}_{50} 40.3 \pm 5 \mu \mathrm{g} / \mathrm{mL}$ ) with reduction of preadipocyte cell growth and intracellular lipid accumulation. Research also revealed an upregulation of adiponectin, the key regulator of insulin sensitivity [140]. Experiments carried out with Rh2 and Rg3 ginsenosides identified in AG preparation revealed that these compounds effectively inhibited adipogenesis. That process was accompanied by the activation of AMPK, which is involved in lipid and cellular energy regulation, as well as inhibition of peroxisome proliferator-activated receptor- $\gamma(\operatorname{PPAR}-\gamma)$, a nuclear receptor. These proteins are recognized as the main regulators of adipogenesis and lipogenesis through their ability to change the expressions of CCAAT/enhancer binding protein $\alpha(\mathrm{C} / \mathrm{EBP}-\alpha)$, adiponectin and leptin, fatty acid binding protein 4 (FABP4), GLUT4, acetyl-CoA carboxylase (ACC), fatty acid synthase (FAS) and perilipin [136]. After adipogenesis induction the expressions of sterol-regulatory-element-binding protein 1 (SREBP1), that is a downstream adipogenic transcriptional regulator of lipogenic genes, was upregulated. However, there is evidence of different mechanism of AG ginsenosides influence on adipogenesis: pseudoginsenoside F11, that is found in AG and not in P. ginseng, promoted adiponectin secretion, fat accumulation and activation of PPAR- $\gamma$ in 3T3-L1 cells [141]. Interestingly, the authors found that simultaneously pseudoginsenoside F11 inhibited obesity-linked phosphorylation of PPAR- $\gamma$ at Ser-273 by Cdk5, which in turn disrupted the contact between PPAR- $\gamma$ and retinoid X receptor RXR $\alpha$, 
which eventually disrupted PPAR- $\gamma / \mathrm{RXR} \alpha$ heterodimer formation and its binding to DNA. Furthermore, Wilson et al. showed that extraction technique determined biological activity of AG preparation [142]. It was observed that water AG extract containing polysaccharides acted as a strong inflammatory modulator, increasing the expression of $I l-6, N F-\kappa B$ and TNF $\alpha$ in adipocytes, whereas the ethanol extract had no such influence. Further studies demonstrated that AG water extract caused a significant increase in the expression of inflammatory genes (Mcp1, TNF $\alpha$, Nos2, Ccl5, Il6) not only in adipocytes, but also in other cells type co-cultured in the presence of adipocytes, like murine macrophages RAW264.7 [143]. Recently, Singh et al. showed beneficial properties of AG ethanol extract on mice deficient in the Pcyt2 (ethanolamine-phosphate cytidylyltransferase 2) gene (ETKO/Pcyt2+/-) [144]. ETKO/Pcyt2+/mice are able to develop fatty liver, obesity, and hypertriglyceridemia, as well as insulin resistance at the age of 25-30 weeks, and these dysfunctional changes are similar to those occurring in humans. Mice treated with AG ( $200 \mathrm{mg} / \mathrm{kg}$ bw for 24 weeks) reduced the fatty liver, hepatic, and intestinal lipoprotein secretion and circulating lipids. More detailed analysis revealed that this was accompanied by a reduction of the expression of the SREBP1, PPAR $\alpha$ and FAS genes in liver. These changes were accompanied by an elevation of AMPK protein level, but without affecting phosphorylation of ACC involved in malonyl-CoA for fatty acid synthesis. AG preparation had no influence on the intestinal expression of fatty acid translocase CD36 and fatty acid transport protein 4 (FATP4) genes in control subjects; however, it downregulated these genes in ETKO/Pcyt2+/- mice intestine.

\subsection{Anti-Aging Properties}

No controlled clinical trials on the influence of AG on life expectancy were performed. Many studies on its effects on both chronological and biological aspects of ageing relate them to antioxidant properties of AG.

AG (2.25 g/ $/ \mathrm{kg}$ for 14 days) was hypothesised to protect against premature ovarian failure (POF), a loss of ovarian function before 40 that can be considered as a marker of accelerated ageing [145]. That study showed that AG protected against POF by regulating prostaglandin biosynthesis, ovulation, and preventing ovarian ageing.

Fernández-Moriano et al. showed that $\mathrm{Rb} 1$, the main ginsenoside of $\mathrm{AG}$, demonstrated neuroprotective potential in SH-SY5Y cells that are a model for neurodegenerative disorders [146]. This effect was manifested mainly by antioxidant action of the ginsenoside: ROS scavenging, increasing the activity of the glutathione system and SOD and activation of the Nrf2 pathway. Moreover, the protective effect against mitochondrial dysfunction was observed, which further supports antioxidant properties of $\mathrm{Rb} 1$ and altogether suggests its potential influence on the pathogenesis of neurodegenerative diseases and in general mitochondria-dependent ageing processes.

Murphy et al. showed that powdered root of AG ( $100 \mathrm{mg} / \mathrm{kg}$ bw for 14 and 28 days) stimulated copulatory behavior of male rats expressed by a decrease in mount, intromission and ejaculation latencies [147]. There were no differences between ginseng-treated and control animals in plasma luteinizing hormone and testosterone, but plasma prolactin levels decreased in the treated rats. It was suggested that ginseng might induce changes in dopaminergic neurotransmission that could contribute to the observed stimulatory effects.

The incidence and prevalence of stroke in general and ischemic stroke in particular increase with age and some features of ischemic stroke are age-related [148]. Brain damage resulting from ischemic stroke is mediated by disturbed flux of $\mathrm{Na}^{+}$ions and drugs blocking voltage-dependent sodium channels are used to protect neurons and other cells during ischemic episodes [149]. Liu et al. showed that water extract of $\mathrm{AG}$ and its main ginsenoside $\mathrm{Rb} 1$ tonically and reversibly blocked the brain in transformed human kidney tsA201 cells transfected with Brain ${ }_{2 a} \alpha$ subunits of the voltage-dependent sodium channel [68]. As effects induced by both whole root extract and isolated $\mathrm{Rb} 1$ were comparable, the authors concluded that $\mathrm{Rb} 1$ might be primarily responsible for the observed effects. Ginseng and $\mathrm{Rb} 1$ induced qualitatively similar effects as lidocaine, a known $\mathrm{Na}+$ channel blocker, so it was 
concluded that the observed blockade was due to the interaction of ginseng/Rb1 with the inactive state of the channel.

Multiple sclerosis (MS) belongs to the most serious of problems in contemporary medical care. Its mechanism is not fully known, but its pathogenesis is associated with overproduction of ROS released by microglia and immune cells infiltrating the central nervous system [150]. These ROS may demyelinate and otherwise damage axons. It was shown that water extract of ginseng $(150 \mathrm{mg} / \mathrm{kg} \mathrm{bw}$ for 14 days) reduced the clinical signs of experimental autoimmune encephalomyelitis (EAE) in mice, an animal model of MS [72]. Ginseng also reduced the extent of demyelination. This improvement of MS-related symptoms was associated with effects, which could contribute to anti-oxidative action of ginseng: decrease in the activity of immunoreactive iNOS and levels of circulating TNF- $\alpha$. As MS is ageing-related disease it can be speculated that the effects of ginseng may be underlined by its general anti-aging action.

Alzheimer's disease (AD), similarly to MS, is a chronic neurodegenerative disease affecting primarily the elderly with no effective treatment available [151]. In AD, the presynaptic cholinergic system is degenerated with the involvement of amyloid-beta $(\mathrm{A} \beta)$ peptides, resulting in decreased activity of ChAT and, consequently, diminished levels of AChE. It was observed that an extract from AG containing high concentration of Rb1 ginsenoside protected human neural stem cells from toxicity induced by synthetic $A \beta_{1-42}$ peptide [64]. The extract also restored the expression of the ChAT gene suppressed by $A \beta_{1-42}$. Injection of the peptide into the brain of experimental mice worsened their cognitive function that were recovered by oral administration of the ginseng extract, which also restored some biochemical markers disturbed by $\mathrm{A} \beta_{1-42}$ injection: microtubule-associated protein 2 (MAP2), synaptophysin and AChE. Therefore, the beneficial action of ginseng might be associated with restoring neuronal integrity disrupted by $\mathrm{A} \beta$ peptides. Decreased levels of synaptophysin, observed in $\mathrm{AD}$ patients, are associated with impaired cognitive functions [152]. It is not completely clear whether the protective effect of ginseng against $A \beta_{1-42}$ peptide was attributed to its degradation or ameliorating of effects already induced by the peptide. The mechanism of the former effect can be partly explained by the observed increase in the activity of neprilysin, an A $\beta$-degrading enzyme, by $\operatorname{Rg} 3$ [153]. However, Al-Hazmi et al. reported that ginseng extract (100 and $200 \mathrm{mg} / \mathrm{kg}$ bw for 14 days) improved memory through recovery of $\mathrm{AChE}$ and restoration of other functions in rat brain [154]. Therefore, further study is needed to determine the potential effects of ginseng in $\mathrm{AD}$ through direct degradation of $\mathrm{Ab}$ peptides and ameliorating of effects of their detrimental action.

AG extract (administered in dose $8 \mathrm{~g} / \mathrm{kg}$ for 12-33 days) was shown to improve some cognitive functions affected by ageing in rats [155]. Free-radical theory of ageing says that ageing is associated with increased ROS production and these ROS damage different tissues leading to the accumulation of abnormalities and progressive deterioration of basic vital functions [156]. However, contemporary theories of ageing do not consider ROS overproduction as the decisive aspect of ageing, but ROS still play an important role in ageing as both the signalling molecules and a damaging/interfering factor [157].

Scholey et al. showed AG extract (doses 100, 200 and $400 \mathrm{mg}$ ) to enhance neurocognitive functions which was manifested by an improvement in working memory performance in an acute, randomised, placebo-controlled, cross-over study. No effect on blood glucose level was observed [68]. It was suggested that profitable effects of ginseng root on memory are due to its main ginsenoside $\mathrm{Rb} 1$ that could induce such effects by improving cholinergic metabolism. These studies were supported by Shi et al. who demonstrated a beneficial effect of AG on the neurocognitive functions in the SAMP10 substrain of senescence-accelerated mice (SAM) [158]. These mice show features of accelerated ageing, including cognitive dysfunctions and loss of neocortical synapses, which can be involved in intellectual decline in aged people. Enhancement in neurocognitive functions in SAM mice was attributed to the upregulation of insulin and choline acetyltransferase.

All of this data serve as rationale for further study of the potential modulation of both chronological and biological aging by AG. 


\section{Interactions of American Ginseng with Microorganisms}

\subsection{Antimicrobial Action}

Sienkiewicz et al. compared efficiency of different parts of the plant: leaves, stalks, hairy roots and field roots. Results of the trial showed that ginsenosides originated from AG (minimal inhibitory concentration-MIC values from 0.5 to $1.7 \mathrm{mg} / \mathrm{mL}$ ) possessed anti-staphylococcal activity. Moreover, antibiotic resistance in Staphylococcus aureus did not influence this feature. It was noted that not only leaves and field roots, but also hairy root cultures are a source of active compounds of AG [159]. Study conducted by Wang et al. [160] indicated antimicrobial activity of AG against two strains of Propionibacterium acnes (MIC 64 and $128 \mu \mathrm{g} / \mathrm{mL}$ ) and Staphylococcus epidermidis (MIC $4.1 \mathrm{mg} / \mathrm{mL}$ ). Less polar ginsenosides, including Rg2, Rg3, Rg6/F4, Rs3, and Rg5/Rk1 exerted greater antimicrobial activity than their polar counterparts ( $\mathrm{Rg} 1, \mathrm{Re}, \mathrm{Rb} 1, \mathrm{Rc}, \mathrm{Rb} 2, \mathrm{Rd})$. These results suggest that less polar fraction of ginsenosides might be used to produce innovative type of antimicrobial agents, including skin care products for prevention and treatment of acne [160]. Kochan et al. showed antimicrobial potential of AG against various pathogenic bacterial and yeast strains [64]. Extracts obtained from three different clones of AG hairy roots inhibited growth of S. aureus, Enterococcus spp., E. coli, Pseudomonas aeruginosa (MIC values from 0.8 to $1.4 \mathrm{mg} / \mathrm{mL}$ ) and yeasts belonging to Candida albicans species (MIC values from 1.0 to $1.4 \mathrm{mg} / \mathrm{mL}$ ). The strongest effects were observed for Gram negative E. coli strains. Enterococcus spp. was the most resistant to activity of extracts [64]. Alipour et al. showed similar effect in the P. aeruginosa O1 strain. AG extract (1.25-5\% w/v) detached bacteria biofilm in microplates and led to reduction in number of living cells [161].

Xue et al. showed an inhibitory effect of AG ginsenosides on Fusobacterium nucleatum, Porphyromonas gingivalis, Porphyromonas endodontalis and Prevotella intermedia that may be involved in halitosis [162]. The effect was more pronounced for less polar ginsenosides that could destroy bacterial cell membrane more easily than they more polar counterparts. Apart from that a homodimeric protein quinqueginsin isolated from the root of AG exerted various antifungal activities against Fusarium oxysporum, Rhizoctonia solani and Coprinus comatus as well as degraded tRNA in yeasts. It also demonstrated antiviral activity by inhibition of human immunodeficiency virus- 1 reverse transcriptase [163].

\subsection{Metabolism of American Ginseng Ginsenosides by Intestinal Microbiota}

Human intestinal microbiota has a significant impact on the metabolism of ginseng saponins. After ingestion, ginsenosides undergo extensive biotransformation [164]. Hydrophilic constituents are metabolized to hydrophobic compounds. The absorption of the metabolites increases with the activity of faecal gut microbiota responsible for metabolism of ginseng saponins. Those metabolites, e.g., compound K, can display higher activity than parental substances [165]. Wan et al. showed the presence of 25 metabolites of ginsenosides from AG root extract mixed with intestinal microbiota isolated from human faeces [166]. Fifteen of them were derivatives of original PPD saponins, 7-metabolites of PPT and remaining 3 of oleanolic acid. These results indicate that the PPD-type ginsenosides were metabolized more efficiently than others. Main metabolic pathways were deglycosylation performed by sequential cleavage of sugar moieties and dehydration. The most frequently found metabolites were ginsenoside Rg3, F2 and compound K. Another study determined metabolites of ginsenosides in human plasma, urine and faeces after ingestion of AG extract by male volunteers [167]. By means of liquid chromatography coupled with quadrupole time-of-flight mass spectrometry 15 peaks were observed in plasma. Ten peaks represented parental ginsenosides and 5-their metabolites. Ginsenosides 20S-Rg2, 20R-Rg2, F2, 20R-Rg3, and compound K were the most abundant in plasma. Twenty peaks were observed in urine; 10 of original ginsenosides and 10 of metabolites. Ginsenosides 20S-Rg2, 20R-Rg2, 20S-Rh1, 20R-Rh1, F1, F2, 20R-Rg3, 20S-Rh2, 20R-Rh and compound K were the major metabolites found in urine. In faeces as many as 36 peaks were detected. Twenty of them represented original ginsenosides and 16-their metabolites. Therefore, metabolism of ginsenosides may play a crucial role 
in their bioactivity. Compound K, the main metabolite of the PPD group, displays higher activity than its parental compound $\mathrm{Rb} 1$ [167].

An AG fortified yogurt containing probiotic Lactobacillus rhamnosus GR-1was developed to improve the beneficial effects of AG [168]. It was observed that in the case of bacteria culture with applied aqueous ginseng extract viability of $L b$. rhamnosus GR-1 was greater in comparison to the culture without AG extract during the 28-day storage period. The results suggested that aqueous AG extract maintained a synbiotic relationship with probiotic strain of Lb. rhamnosus GR-1 [168].

AG influence on gut microorganisms was investigated in mice with chemically induced colitis [169]. This study showed that AG decreased the growth of bacteria belonging to Bacteroidetes and Verrucomicrobia and increased growth of Firmicutes, suggesting that AG could restore composition of normal gut microbiota disturbed by pathological processes associated with colitis formation.

\section{Conclusions and Perspectives}

AG has been applied for centuries as a diet supplement due to a chemical composition rich in active compounds: ginsenosides. These saponins belonging to a group of glycosides are responsible for wide range of health-beneficial activities of the plant and may allow to distinguish AG from other Panax species. AG is also rich in unsaturated fatty acids, linoleic and linolenic, which are important for proper function of the human organism. Different parts of the plant, the leaves, stem, flowers, berries and primarily roots (raw or thermally processed), can be a raw material for production of extracts. There are many commercial products containing AG extracts, including shredded slices, drinks, alcoholic beverages and dried sugar coated roots. Also, AG is used in cosmetics such as shower gels, hair conditioners, lotions, and shampoos [28].

This review highlights the most important characteristics and possible applications of AG. Among numerous studies AG was documented to exert beneficial activity towards nervous system. It boosts memory, increases calmness, and enhances cognitive performance [68]. It has therapeutic potential in treatment of Alzheimer disease and anxiety [64,66]. It also affects cardiovascular system-changes cardiac structure in hypertension, reduces heart rate, inhibits hypertrophy and heart failure $[79,81,128,170]$. Furthermore, AG prevents oesophageal damage resulted from reflux oesophagitis and formation of ulcer in gastric mucosa $[84,85]$. Apart from that, it displays antimicrobial activity against different pathogenic strains of bacteria including resistant to antibiotics S. aureus strain [159]. AG is extensively investigated in terms of anti-cancer activity. It promotes apoptosis of cancer cells and alters many different signalling pathways important for cancer transformation [92-98,171]. It also protects normal cells from unwanted side effects of anti-cancer drugs and diminishes cancer-related fatigue $[100,110]$. However, the mechanisms underlying beneficial activity of AG in cancer is not fully understood. Administration of AG may be beneficial for individuals suffering from obesity and diabetes. It enhances sensitivity of tissues to insulin and inhibits formation of adipose tissue. Also, polysaccharides of AG were reported to display pro-health effects by stimulating the immune system. Assinewe et al. observed that polysaccharide of AG extract containing glucose, galactose, arabinose, rhamnose, and mannose displayed cytokine-stimulating activity on macrophages. In this study, aqueous extracts of AG roots $(1-100 \mu \mathrm{g} / \mathrm{mL})$ stimulated the release of immunoreactive $\mathrm{TNF}$, contributing to the activation of macrophages [172]. Yu et al. also showed immunostimulatory effect of the fraction of polysaccharide present in AG extract $(50-400 \mu \mathrm{g} / \mathrm{mL})$. AG extract application led to enhancement of splenic lymphocyte proliferation, macrophage phagocytosis and nitric oxide production [173]. AG extract (125 mg/kg for 3-6 days) stimulated alveolar macrophages in rats associated with increased level of NO, TNF- $\alpha$ and IL-6 in plasma [174]. These results were in agreement with those obtained by Azike. Similarly, AdG water extract $(125 \mathrm{mg} / \mathrm{kg})$ administered to rats for 3-6 days upregulated nitric oxide, TNF- $\alpha$ and IL-6. Within in vitro study macrophages were incubated with different concentrations of AG. A dose-dependent immunostimulatory activity of aqueous and alcohol extracts of AG (50-200 $\mu \mathrm{g} / \mathrm{mL})$ in rat macrophages was observed and an in vitro effect was more pronounced than corresponding in vivo result due to relatively low bioavailability of the extract 
administrated orally [175]. As the methodology of AG separation is poorly developed, it is a promising direction for the future research.

Although many health beneficial pharmaceutical effects have been attributed to AG, molecular mechanisms underlying these effects are poorly known. Usually, studies showing a biological/medical effect of AG or its component, suggest more than only one molecular target. This follows from the fact that pharmaceutical effects of AG may be underlined by several mechanisms of its action with many possible molecular targets linked with each of the mode of action. Therefore, we have not attempted to comprehensively address the problem of identifying molecular targets of AG as the length of this review is limited. Excellent reviews on this subject can be found elsewhere [9-12,176,177].

Most health effects of AG are mainly due to its strong antioxidant properties. In general, AG is frequently considered to have a greater capacity for free radicals scavenging and inhibit lipid peroxidation than its Asian counterpart [178]. To investigate mechanisms beyond antioxidant activity of AG, Kitts et al. showed that its extract containing main ginsenosides was able to scavenge DPPH (2,2-diphenyl-1-picrylhydrazyl)-stable free radical as well as and peroxyl (LOO•) and hydroxyl $(\bullet \mathrm{OH})$ free radicals [179]. Moreover, the extract efficiently chelated transition metals, preventing their involvement in the Fenton reaction, which was confirmed by inhibition of the induction of DNA strand breaks and suppression of protein oxidation. Additionally, the extract displayed protective action against lipid peroxidation in a metal-free solution. This important study shows the potential of AG to exert an antioxidant action by scavenging free radicals, chelating Fenton metals and preventing lipid peroxidation to further investigations in biological systems. These results were confirmed in a significant range in V79-4 Chinese hamster fibroblast-like cell line incubated with steamed root (red ginseng) of AG [26].

In spite of wide range of beneficial activities towards human organism, AG is not recommended for women during pregnancy and lactation period, because its teratogenic effects in rats and mice embryos as well as its not reported safety in breast-feeding women [180,181]. Because it has a cooling effect on the body, it is recommended to be consumed in summer [167]. Overdose of AG extract may lead to appearance of side effects such as insomnia, nervousness, gastrointestinal track disorders and symptoms of depression [27]. Components of AG extract may demonstrate antagonistic activity on drugs, such as anticoagulants, prescribed for chronic atrial fibrillation, mechanical valves, deep vein thrombosis and recurrent stroke [171]. It is difficult to determine the effective preventive and therapeutic concentrations of AG, because different units (e.g., $\mathrm{mg} / \mathrm{kg} b \mathrm{~b}, \mathrm{mg} / \mathrm{mL}, \mathrm{mg}$ ) and time of application (e.g., 4 times in $2 \mathrm{~h}$ interval; twice in $4 \mathrm{~h}$ interval; for $12 \mathrm{~h}$; for 2, 10, 12, 14, 30 or 33 days; for 10 or 24 weeks; for 3 months) are used in different studies. For this reason, it is not possible to make a comprehensive summary of effective preventive and therapeutic doses of AG, and it needs standardisation.

Currently, AG is a promising source of health beneficial phytochemicals. In view of its foregoing pro-health activity, possible mechanisms responsible for its mode of action and potential of application in different branches of medicine are worth further investigation. There are very few studies on AG interactions with probiotics in terms of its stimulatory or inhibitory activity on growth of certain strains of these beneficial microorganisms [165]. Apart from that, there is not much information about AG interactions with normal human microbiota, its influence on ginsenosides transformation, and their biological activity in the human body [165-167]. The antibiotic effect of AG towards pathogenic strains also requires more extensive investigation [159-163]. American Ginseng still has great potential to be explored in both basal research and clinical medicine.

Author Contributions: D.S. conceptualization, writing—original draft preparation, writing—review and editing; A.N. conceptualization, supervision, writing-original draft preparation, writing-review and editing; J.B. conceptualization, writing-original draft preparation, writing-review and editing; M.Z.-S., E.K., G.S. and I.M. writing-original draft preparation.

Funding: This research received no external funding.

Conflicts of Interest: The authors declare no conflict of interest. 


\section{References}

1. Ahmad, Z.; Hassan, S.S.; Azim, S. A therapeutic connection between dietary phytochemicals and ATP synthase. Curr. Med. Chem. 2017, 24, 3894-3906. [CrossRef]

2. Lee, G.; Bae, H. Therapeutic effects of phytochemicals and medicinal herbs on depression. BioMed Res. Int. 2017, 2017, 6596241. [CrossRef] [PubMed]

3. He, Y.S.; Sun, W.; Wang, C.Z.; Qi, L.W.; Yang, J.; Li, P.; Wen, X.D.; Yuan, C.S. Effects of American ginseng on pharmacokinetics of 5-fluorouracil in rats. Biomed. Chromatogr. 2014, 29, 762-767. [CrossRef] [PubMed]

4. Li, J.; Ichikawa, T.; Jin, Y.; Hofseth, L.J.; Nagarkatti, P.; Nagarkatti, M.; Windust, A.; Cui, T. An essential role of Nrf2 in American ginseng-mediated anti-oxidative actions in cardiomyocytes. J. Ethnopharmacol. 2010, 130, 222-230. [CrossRef] [PubMed]

5. Shergis, J.L.; Di, Y.M.; Zhang, A.L.; Vlahos, R.; Helliwell, R.; Ye, J.M.; Xue, C.C. Therapeutic potential of Panax ginseng and ginsenosides in the treatment of chronic obstructive pulmonary disease. Complement. Ther. Med. 2014, 22, 944-953. [CrossRef] [PubMed]

6. Rotem, C.; Kaplan, B. Phyto-female complex for the relief of hot flushes, night sweats and quality of sleep: Randomized, controlled, double-blind pilot study. Gynecol. Endocrinol. 2007, 23, 117-122. [CrossRef]

7. McGraw, J.B.; Lubbers, A.E.; Van der Voort, M.; Mooney, E.H.; Furedi, M.A.; Souther, S.; Turner, J.B.; Chandler, J. Ecology and conservation of ginseng (Panax quinquefolius) in a changing world. Ann. N. Y. Acad. Sci. 2013, 1286, 62-91. [CrossRef] [PubMed]

8. Wang, Y.; Choi, H.K.; Brinckmann, J.A.; Jiang, X.; Huang, L. Chemical analysis of Panax quinquefolius (North American ginseng): A review. J. Chromatogr. A 2015, 1426, 1-15. [CrossRef]

9. Qi, L.W.; Wang, C.Z.; Yuan, C.S. Ginsenosides from American ginseng: Chemical and pharmacological diversity. Phytochemistry 2011, 72, 689-699. [CrossRef] [PubMed]

10. Mohanan, P.; Subramaniyam, S.; Mathiyalagan, R.; Yang, D.C. Molecular signaling of ginsenosides Rb1, Rg1, and Rg3 and their mode of actions. J. Ginseng Res. 2018, 42, 123-132. [CrossRef] [PubMed]

11. Liu, L.; Anderson, G.A.; Fernandez, T.G.; Doré, S. Efficacy and mechanism of Panax ginseng in experimental stroke. Front. Neurosci. 2019, 2013, 1-20. [CrossRef]

12. Nakhjavani, M.; Hardingham, J.E.; Palethorpe, H.M.; Tomita, Y.; Smith, E.; Price, T.J.; Townsend, A.R. Ginsenoside Rg3: Potential molecular targets and therapeutic indication in metastatic breast cancer. Medicines 2019, 6, 17. [CrossRef]

13. Yu, C.; Wang, C.Z.; Zhou, C.J.; Wang, B.; Han, L.; Zhang, C.F.; Wu, X.H.; Yuan, C.S. Adulteration and cultivation region identification of American ginseng using HPLC coupled with multivariate analysis. J. Pharm. Biomed. Anal. 2014, 99, 8-15. [CrossRef] [PubMed]

14. Lee, D.G.; Jang, S.I.; Kim, Y.R.; Yang, K.E.; Yoon, S.J.; Lee, Z.W.; An, H.J.; Jang, I.S.; Choi, J.S.; Yoo, H.S. Anti-proliferative effects of ginsenosides extracted from mountain ginseng on lung cancer. Chin. J. Integr. Med. 2016, 2, 344-352. [CrossRef]

15. Yang, L.; Yu, Q.T.; Ge, Y.Z.; Zhang, W.S.; Fan, Y.; Ma, C.W.; Liu, Q.; Qi, L.W. Distinct urine metabolome after Asian ginseng and American ginseng intervention based on GC-MS metabolomics approach. Sci. Rep. 2018, 6, 39045. [CrossRef] [PubMed]

16. Lee, O.R.; Nguyen, N.Q.; Lee, K.H.; Kim, Y.C.; Seo, J. Cytohistological study of the leaf structures of Panax ginseng Meyer and Panax quinquefolius L. J. Ginseng Res. 2016, 41, 463-468. [CrossRef]

17. Pan, Y.; Wang, X.; Sun, G.; Li, F.; Gong, X. Application of RAD sequencing for evaluating the genetic diversity of domesticated Panax notoginseng (Araliaceae). PloS ONE 2016, 11, e0166419. [CrossRef] [PubMed]

18. Cruse-Sanders, J.M.; Hamrick, J.L. Genetic diversity in harvested and protected populations of wild American ginseng, Panax quinquefolius L. (Araliaceae). Am. J. Bot. 2004, 91, 540-548. [CrossRef]

19. Jia, L.; Zhao, Y. Current evaluation of the millennium phytomedicine-ginseng (I): Etymology, pharmacognosy, phytochemistry, market and regulations. Curr. Med. Chem. 2009, 16, 2475-2484. [CrossRef] [PubMed]

20. Qin, Z.; Jia, C.; Liao, D.; Chen, X.; Li, X. Comparison of serum metabolite changes of radiated mice administered with Panax quinquefolium from different cultivation regions using UPLC-Q/TOF-MS based metabolomic approach. Molecules 2018, 23, 1014. [CrossRef] [PubMed]

21. Souther, S.; Lechowicz, M.J.; McGraw, J.B. Experimental test for adaptive differentiation of ginseng populations reveals complex response to temperature. Ann. Bot. 2012, 110, 829-837. [CrossRef] 
22. Pengelly, A.; Bennett, K. Appalachian Plant Monographs: Panax quinquefolius L., American Ginseng. Available online: http://www.frostburg.edu/aces/appalachian-plants/ (accessed on 5 January 2019).

23. Lim, W.; Mudge, K.W.; Vermeylen, F. Effects of population, age and cultivation methods on ginsenoside content of wild American ginseng (Panax quinquefolium). J. Agric. Food Chem. 2005, 53, 8498-8505. [CrossRef] [PubMed]

24. Proctor, J.T.; Shelp, B.J. Effect of boron nutrition on American ginseng in field and in nutrient cultures. J. Ginseng Res. 2013, 38, 73-77. [CrossRef] [PubMed]

25. Lee, J.S.; Bae, I. Quality Characteristics, changes in physiochemical properties and functional properties of camembert cheese containing red ginseng powder. Korean J. Food Sci. Anim. Resour. 2018, 38, 64-77. [CrossRef] [PubMed]

26. Kim, K.T.; Yoo, K.M.; Lee, J.W.; Eom, S.H.; Hwang, I.K.; Lee, C.Y. Protective effect of steamed American ginseng (Panax quinquefolius L.) on V79-4 cells induced by oxidative stress. J. Ethnopharmacol. 2007, 111, 443-450. [CrossRef] [PubMed]

27. Dolot, M.; Smigielski, K.; Wesolowska, M. Analysis of chosen nutrients in American ginseng (Panax quinquefolium L.) cultivated in Poland. Sci. Pap. Tech. Univ. Lodz Food Chem. Biotechnol. 2006, 70, 53-63.

28. Sengupta, S.; Toh, S.A.; Sellers, L.A.; Skepper, J.N.; Koolwijk, P.; Leung, H.W.; Yeung, H.W.; Wong, R.N.; Sasisekharan, R.; Fan, T.P. Modulating angiogenesis: The yin and the yang in ginseng. Circulation 2004, 110, 1219-1225. [CrossRef]

29. Jung, J.; Kim, K.H.; Yang, K.; Bang, K.H.; Yang, T.J. Practical application of DNA markers for high-throughput authentication of Panax ginseng and Panax quinquefolius from commercial ginseng products. J. Ginseng Res. 2014, 38, 123-129. [CrossRef]

30. Ma, Z.N.; Li, Y.Z.; Li, W.; Yan, X.T.; Yang, G.; Zhang, J.; Zhao, L.C.; Yang, L.M. Nephroprotective effects of saponins from leaves of Panax quinquefolius against cisplatin-induced acute kidney injury. Int. J. Mol. Sci. 2017, 18, 1407. [CrossRef]

31. Nag, S.A.; Qin, J.; Wang, W.; Wang, M.H.; Wang, H.; Zhang, R. Ginsenosides as anticancer agents: In Vitro and in vivo activities, structure-activity relationships and molecular mechanisms of action. Front. Pharmacol. 2012, 3, 25. [CrossRef]

32. Kochan, E.; Szymczyk, P.; Kuźma, Ł.; Lipert, A.; Szymańska, G. Yeast extract stimulates ginsenoside production in hairy root cultures of American ginseng cultivated in shake flasks and nutrient sprinkle bioreactors. Molecules 2017, 22, 880. [CrossRef] [PubMed]

33. Feng, R.; Liu, J.; Wang, Z.; Zhang, J.; Cates, C.; Rousselle, T.; Meng, Q.; Li, J. The structure-activity relationship of ginsenosides on hypoxia-reoxygenation induced apoptosis of cardiomyocytes. Biochem. Biophys. Res. Commun. 2017, 494, 556-568. [CrossRef] [PubMed]

34. Yang, W.Z.; Hu, Y.; Wu, W.Y.; Ye, M.; Guo, D.A. Saponins in the genus Panax L. (Araliaceae): A systematic review of their chemical diversity. Phytochemistry 2014, 106, 7-24. [CrossRef] [PubMed]

35. Wang, A.B.; Wang, C.Z.; Wu, J.A.; Osinski, J.; Yuan, C.S. Determination of major ginsenosides in Panax quinquefolius (American ginseng) using high-performance liquid chromatography. Phytochem. Anal. 2005, 16, 272-277. [CrossRef] [PubMed]

36. Shukla, Y.N.; Tripathi, A.K.; Mehta, V.K. Feeding-deterrency of oleanolic acid isolated from Panax quinquefolium against lepidopterans. Phytother. Res. 1997, 11, 591-593. [CrossRef]

37. Huang, X.; Liu, Y.; Zhang, N.; Sun, X.; Yue, H.; Chen, C.; Liu, S. UPLC Orbitrap HRMS analysis of Panax quinquefolium L. for authentication of Panax genus with chemometric methods. J. Chromatogr. Sci. 2018, 56, 25-35. [CrossRef] [PubMed]

38. Kim, D.H. Chemical diversity of Panax ginseng, Panax quinquefolium, and Panax notoginseng. J Ginseng Res. 2012, 36, 1-15. [CrossRef]

39. Liu, Y.Y.; Zhang, T.Y.; Xue, X.; Liu, D.M.; Zhang, H.T.; Yuan, L.L.; Liu, Y.L.; Yang, H.L.; Sun, S.B.; Zhang, C.; et al. Pseudoginsenoside-F11 attenuates cerebral ischemic injury by alleviating autophagic/lysosomal defects. CNS Neurosci. Ther. 2017, 23, 567-579. [CrossRef]

40. Popovich, D.G.; Yeo, C.R.; Zhang, W. Ginsenosides derived from Asian (Panax ginseng), American ginseng (Panax quinquefolius) and potential cytoactivity. Int. J. Biomed. Pharma. Sci. 2012, 6, 56-62.

41. Zhang, X.J.; Huang, L.L.; Cai, X.J.; Li, P.; Wang, Y.T.; Wan, J.B. Fatty acid variability in three medicinal herbs of Panax species. Chem. Cent. J. 2013, 7, 12. [CrossRef] 
42. Wang, M.; Guilbert, L.J.; Li, J.; Wu, Y.; Pang, P.; Basu, T.K.; Shan, J.J. A proprietary extract from north American ginseng (Panax quinquefolium) enhances IL-2 and IFN-gamma productions in murine spleen cells induced by Con-A. Int. Immunopharmacol. 2004, 4, 311-315. [CrossRef] [PubMed]

43. Wang, L.; Yu, X.; Yang, X.; Li, Y.; Yao, Y.; Lui, E.M.K.; Ren, G. Structural and anti-inflammatory characterization of a novel neutral polysaccharide from North American ginseng (Panax quinquefolius). Int. J. Biol. Macromol. 2015, 74, 12-17. [CrossRef] [PubMed]

44. Ludwiczuk, A.; Wolski, T.; Hołderna-Kędzia, E. Estimation of the chemical composition and antimicrobial and antioxidant activity of extracts received from leaves and roots of American ginseng (Panax quinquefolium L.). Herba Pol. 2006, 52, 79-90.

45. Cui, S.; Wu, J.; Wang, J.; Wang, X. Discrimination of American ginseng and Asian ginseng using electronic nose and gas chromatography mass spectrometry coupled with chemometrics. J. Ginseng Res. 2017, 41, 85-95. [CrossRef]

46. Kochan, E.; Szymczyk, P.; Kuźma, Ł.; Szymańska, G.; Wajs-Bonikowska, A.; Bonikowski, R.; Sienkiewicz, M. The increase of triterpene saponin production induced by trans-anethole in hairy root cultures of Panax quinquefolium. Molecules 2018, 23, 2674. [CrossRef] [PubMed]

47. Wang, C.Z.; Cai, Y.; Anderson, S.; Yuan, C.S. Ginseng metabolites on cancer chemoprevention: An angiogenesis link? Diseases 2015, 3, 193-204. [CrossRef]

48. Sun, J.; Chen, P. Differentiation of Panax quinquefolius grown in the USA and China using LC/MS-based chromatographic fingerprinting and chemometric approaches. Anal. Bioanal. Chem. 2011, 399, 1877-1889. [CrossRef]

49. Sun, X.; Chen, P.; Cook, S.L.; Jackson, G.P.; Harnly, J.M.; Harrington, P.B. Classification of cultivation locations of Panax quinquefolius $\mathrm{L}$ samples using high performance liquid chromatography-electrospray ionization mass spectrometry and chemometric analysis. Anal. Chem. 2012, 84, 3628-3634. [CrossRef] [PubMed]

50. Kochan, E.; Kołodziej, B.; Gadomska, G.; Chmiel, A. Content of ginsenosides in Panax quinquefolium from field cultivation. Herba Pol. 2004, 50, 20-27. [CrossRef]

51. Xiao, D.; Yue, H.; Xiu, Y.; Sun, X.; Wang, Y.B.; Liu, S.Y. Accumulation characteristics and correlation analysis of five ginsenosides with different cultivation ages from different regions. J. Ginseng Res. 2015, 39, 338-344. [CrossRef]

52. Liu, Y.; Wang, X.; Wang, L.; Chen, X.; Pang, X.; Han, J. A Nucleotide signature for the identification of American ginseng and its products. Front. Plant Sci. 2016, 7, 319. [CrossRef]

53. Mancuso, C.; Santangelo, R. Panax ginseng and Panax quinquefolius: From pharmacology to toxicology. Food Chem. Toxicol. 2017, 107, 362-372. [CrossRef] [PubMed]

54. Wolski, T.; Ludwiczuk, A.; Baj, T.; Głowniak, K.; Świątek, M. Genus Panax-Taxonomy, chemical composition, pharmacological effects, medicinal application and phytochemical analysis of aerial and underground parts of American ginseng-Panax quinquefolium 1. Part I. Post. Fitoterapii 2008, 2, 94-114.

55. Chen, C.; Chiou, W.; Zhang, J. Comparison of the pharmacological effects of Panax ginseng and Panax quinquefolium. Acta Pharmacol. Sin. 2008, 29, 1103-1108. [CrossRef] [PubMed]

56. Park, J.D.; Rhee, D.K.; Lee, Y.H. Biological activities and chemistry of saponins from Panax ginseng C.A. Meyer. Phytochem. Rev. 2005, 4, 159-175. [CrossRef]

57. Rokot, N.T.; Kairupan, T.S.; Cheng, C.-H.; Runtuwene, J.; Kapantow, N.H.; Amitani, M.; Morinaga, A.; Amitani, H.; Asakawa, A.; Inui, A. A Role of ginseng and its constituents in the treatment of central nervous system disorders. Evid. Based Complement. Alternat. Med. 2016, 2016, 2614742. [CrossRef] [PubMed]

58. Popovich, D.G.; Kitts, D.D. Generation of ginsenosides Rg3 and Rh2 from North American ginseng. Phytochemistry 2004, 65, 337-344. [CrossRef]

59. Rasheed, N.; Tyagi, E.; Ahmad, A.; Siripurapu, K.B.; Lahiri, S.; Shukla, R.; Palit, G. Involvement of monoamines and proinflammatory cytokines in mediating the anti-stress effects of Panax quinquefolium. J. Ethnopharmacol. 2008, 117, 257-262. [CrossRef]

60. Xu, H.; Yu, X.; Qu, S.; Chen, Y.; Wang, Z.; Sui, D. In vive and in vitro cardioprotective effects of Panax quinquefolium 20(S)-protopanaxadiol saponins (PQDS), isolated from Panax quinquefolium. Pharmazie 2013, 68, 287-292.

61. Wang, M.; Guilbert, L.J.; Ling, L.; Li, J.; Wu, Y.; Xu, S.; Pang, P.; Shan, J.J. Immunomodulating activity of CVT-E002, a proprietary extract from North American ginseng (Panax quinquefolium). J. Pharma Pharmacol. 2001, 53, 1515-1523. [CrossRef] 
62. Xie, G.; Wang, C.Z.; Yu, C.; Qiu, Y.; Wen, X.D.; Zhang, C.F.; Yuan, C.S.; Jia, W. Metabonomic profiling reveals cancer chemopreventive effects of American ginseng on colon carcinogenesis in Apc(Min/+) mice. J. Proteome Res. 2015, 14, 3336-3347. [CrossRef]

63. Kochan, E.; Wasiela, M.; Sienkiewicz, M. The production of ginsenosides in hairy root cultures of American ginseng, Panax quinquefolium L. and their antimicrobial activity. In Vitro Cell Dev. Biol. Plant 2012, 49, $24-29$. [CrossRef] [PubMed]

64. Shin, K.; Guo, H.; Cha, Y.; Ban, Y.H.; Seo, D.W.; Choi, Y.; Kim, T.S.; Lee, S.P.; Kim, J.C.; Choi, E.K.; et al. Cereboost $^{\mathrm{TM}}$ an American ginseng extract improves cognitive function via up-regulation of choline acetyltransferase expression and neuroprotection. Regul. Toxicol. Pharmacol. 2016, 78, 53-58. [CrossRef]

65. Bandelow, B.; Michaelis, S. Epidemiology of anxiety disorders in the 21st century. Dialogues Clin. Neurosci. 2015, 17, 327-335. [PubMed]

66. Wei, X.Y.; Yang, J.Y.; Wang, J.H.; Wu, C.F. Anxiolytic effect of saponins from Panax quinquefolium in mice. J. Ethnopharmacol. 2007, 111, 613-618. [CrossRef] [PubMed]

67. Scholey, A.; Ossoukhova, A.; Owen, L.A.; Pipingas, A.; He, K.; Roller, M.; Stough, C. Effects of American ginseng (Panax quinquefolius) on neurocognitive function: An acute, randomized, double-blind, placebo-controlled, crossover study. Psychopharmacology 2012, 212, 345-356. [CrossRef]

68. Liu, D.; Li, B.; Liu, Y.; Attele, A.S.; Kyle, J.W.; Yuan, C.S. Voltage-dependent inhibition of brain Na+ channels by American ginseng. Eur. J. Pharmacol. 2001, 413, 47-54. [CrossRef]

69. Wang, Y.; Chen, J.; Chu, S.; Wang, Y.; Wang, X.; Chen, N.; Zhang, J. Improvement of memory in mice and increase of hippocampal excitability in rats by ginsenoside Rg1's metabolites ginsenoside Rh1 and protopanaxatriol. J. Pharmacol. Sci. 2009, 109, 504-510. [CrossRef] [PubMed]

70. Wu, C.F.; Liu, Y.L.; Song, M.; Liu, W.; Wang, J.H.; Li, X.; Yang, J.Y. Protective effects of pseudoginsenoside-F11 on methamphetamine-induced neurotoxicity in mice. Pharmacol. Biochem. Behav. 2003, 76, 103-109. [CrossRef]

71. Bowie, L.E.; Roscoe, W.A.; Lui, E.M.K.; Smith, R.; Karlik, S.J. Effects of an aqueous extract of North American ginseng on MOG (35-55)-induced EAE in mice. Can. J. Physiol. Pharmacol. 2012, 90, 933-939. [CrossRef]

72. Sloley, B.D.; Pang, P.K.; Huang, B.H.; Ba, F.; Li, F.L.; Benishin, C.G.; Greenshaw, A.J.; Han, J.J. American ginseng extract reduces scopolamine-induced amnesia in a spatial learning task. J. Psychiat. Neurosci. 1999, 24, 442-452.

73. Wang, J.Y.; Yang, J.Y.; Wang, F.; Fu, S.Y.; Hou, Y.; Jiang, B.; Ma, J.; Song, C.; Wu, C.F. Neuroprotective effect of pseudoginsenoside-f11 on a rat model of Parkinson's disease induced by 6-hydroxydopamine. Evid. Based Complement. Alternat. Med. 2013, 2013, 152798. [CrossRef]

74. Dou, H.C.; Chen, J.Y.; Ran, T.F.; Jiang, W.M. Panax quinquefolius saponin inhibits endoplasmic reticulum stress-mediated apoptosis and neurite injury and improves functional recovery in a rat spinal cord injury model. Biomed. Pharmacother. 2018, 102, 212-220. [CrossRef] [PubMed]

75. Fu, K.; Lin, H.; Miyamoto, Y.; Wu, C.; Yang, J.; Uno, K.; Nitta, A. Pseudoginsenoside-F11 inhibits methamphetamine-induced behaviors by regulating dopaminergic and GABAergic neurons in the nucleus accumbens. Psychopharmacology 2015, 233, 831-840. [CrossRef] [PubMed]

76. Yuan, C.S.; Wang, X.; Wu, J.A.; Attele, A.S.; Xie, J.T.; Gu, M. Effects of Panax quinquefolius L. on brainstem neuronal activities: Comparison between Wisconsin-cultivated and Illinois-cultivated roots. Phytomedicine 2011, 8, 178-183. [CrossRef]

77. Chanana, P.; Kumar, A. GABA-BZD receptor modulating mechanism of Panax quinquefolius against 72-h sleep deprivation induced anxiety like behavior: Possible roles of oxidative stress, mitochondrial dysfunction and neuroinflammation. Front. Neurosci. 2016, 10, 84. [CrossRef]

78. Jiang, Y.; Li, M.; Lu, Z.; Wang, Y.; Yu, X.; Sui, D.; Fu, L. Ginsenoside Rg3 induces ginsenoside Rb1—Comparable cardioprotective effects independent of reducing blood pressure in rats. Exp. Ther. Med. 2017, 14, 4977-4985. [CrossRef]

79. Jiang, M.; Murias, J.M.; Chrones, T.; Sims, S.M.; Lui, E.; Noble, E.G. American ginseng acutely regulates contractile function of rat heart. Front. Pharmacol. 2014, 5, 43. [CrossRef]

80. Xu, H.; Yu, X.; Qu, S.; Chen, Y.; Wang, Z.; Sui, D. Protective effect of Panax quinquefolium 20(S)-protopanaxadiol saponins, isolated from Panax quinquefolium on permanent focal cerebral ischemic injury in rats. Exp. Ther. Med. 2014, 7, 165-170. [CrossRef] 
81. Tang, X.; Gan, X.T.; Rajapurohitam, V.; Huang, C.X.; Xue, J.; Lui, E.M.K.; Karmazyn, M. North American ginseng (Panax quinquefolius) suppresses $\beta$-adrenergic-dependent signalling, hypertrophy, and cardiac dysfunction. Can. J. Physiol. Pharmacol. 2016, 94, 1325-1335. [CrossRef]

82. Wu, Y.; Lu, X.; Xiang, F.L.; Lui, E.M.K.; Feng, Q. North American ginseng protects the heart from ischemia and reperfusion injury via upregulation of endothelial nitric oxide synthase. Pharmacol. Res. 2011, 64, 195-202. [CrossRef]

83. Wu, Y.; Qin, C.; Lu, X.; Marchiori, J.; Feng, Q. North American ginseng inhibits myocardial NOX2-ERK1/2 signaling and tumor necrosis factor-alpha expression in endotoxemia. Pharmacol. Res. 2016, 111, 217-225. [CrossRef]

84. Singh, P.; Singh, N.; Sengupta, S.; Palit, G. Ameliorative effects of Panax quinquefolium on experimentally induced reflux oesophagitis in rats. Indian J. Med. Res. 2012, 135, 407-413.

85. Huang, C.C.; Chen, Y.M.; Wang, D.C.; Chiu, C.C.; Lin, W.T.; Huang, C.Y.; Hsu, M.C. Cytoprotective effect of American ginseng in a rat ethanol gastric ulcer model. Molecules 2013, 19, 316-326. [CrossRef]

86. World Health Organization. Available online: https://www.who.int/cancer/en/ (accessed on 4 February 2019).

87. Zhao, Y.; Hu, X.; Zuo, X.; Wang, M. Chemopreventive effects of some popular phytochemicals on human colon cancer: A review. Food Funct. 2018, 9, 4548-4568. [CrossRef]

88. Dandawate, P.R.; Subramaniam, D.; Jensen, R.A.; Anant, S. Targeting cancer stem cells and signaling pathways by phytochemicals: Novel approach for breast cancer therapy. Semin. Cancer Biol. 2016, 40-41, 192-208. [CrossRef]

89. Rais, J.; Jafri, A.; Siddiqui, S.; Tripathi, M.; Arshad, M. Phytochemicals in the treatment of ovarian cancer. Front. Biosci. 2017, 9, 67-75. [CrossRef]

90. Kumar, N.B.; Krischer, J.P.; Allen, K.; Riccardi, D.; Besterman-Dahan, K.; Salup, R.; Kang, L.; Xu, P.; Pow-Sang, J. Safety of purified isoflavones in men with clinically localized prostate cancer. Nutr. Cancer 2007, 59, 169-175. [CrossRef]

91. Nishino, H. Phytochemicals in hepatocellular cancer prevention. Nutr. Cancer 2009, 61, 789-791. [CrossRef]

92. Yang, J.; Yuan, D.; Xing, T.; Su, H.; Zhang, S.; Wen, J.; Bai, Q.; Dang, D. Ginsenoside Rh2 inhibiting HCT116 colon cancer cell proliferation through blocking PDZ-binding kinase/T-LAK cell-originated protein kinase. J. Ginseng Res. 2016, 40, 400-408. [CrossRef]

93. Yao, H.; Wan, J.Y.; Zeng, J.; Huang, W.H.; Sava-Segal, C.; Li, L.; Niu, X.; Wang, Q.; Wang, C.Z.; Yuan, C.S. Effects of compound $\mathrm{K}$, an enteric microbiome metabolite of ginseng, in the treatment of inflammation associated colon cancer. Oncol. Lett. 2018, 15, 8339-8348. [CrossRef]

94. Gao, J.L.; Lv, G.Y.; He, B.C.; Zhang, B.Q.; Zhang, H.; Wang, N.; Wang, C.Z.; Du, W.; Yuan, C.S.; He, T.C. Ginseng saponin metabolite 20(S)-protopanaxadiol inhibits tumor growth by targeting multiple cancer signaling pathways. Oncol. Rep. 2013, 30, 292-298. [CrossRef] [PubMed]

95. Yu, C.; Wen, X.D.; Zhang, Z.; Zhang, C.F.; Wu, X.H.; Martin, A.; Du, W.; He, T.C.; Wang, C.Z.; Yuan, C.S. American ginseng attenuates azoxymethane/dextran sodium sulfate-induced colon carcinogenesis in mice. J. Ginseng Res. 2014, 39, 14-21. [CrossRef]

96. Qu, Y.; Wang, Z.; Zhao, F.; Liu, J.; Zhang, W.; Li, J.; Xu, H. AFM-detected apoptosis of hepatocellular carcinoma cells induced by American ginseng root water extract. Micron 2018, 104, 1-7. [CrossRef]

97. King, M.; Murphy, L. American ginseng (Panax quinquefolius L.) extract alters mitogen-activated protein kinase cell signaling and inhibits proliferation of MCF-7-cells. J. Exp. Ther. Oncol. 2007, 6, 147-155. [PubMed]

98. Li, B.; Wang, C.Z.; He, T.C.; Yuan, C.S.; Du, W. Antioxidants potentiate American ginseng-induced killing of colorectal cancer cells. Cancer Lett. 2010, 289, 62-70. [CrossRef] [PubMed]

99. Blasiak, J. DNA-damaging anticancer drugs - A Perspective for DNA repair- oriented therapy. Curr. Med. Chem. 2017, 24, 1488-1503. [CrossRef]

100. Pawar, A.A.; Tripathi, D.N.; Ramarao, P.; Jena, G. Protective effects of American ginseng (Panax quinquefolium) against mitomycin C induced micronuclei in mice. Phytother. Res. 2007, 21, 1221-1227. [CrossRef]

101. Oun, R.; Moussa, Y.E.; Wheate, N.J. The side effects of platinum-based chemotherapy drugs: A review for chemists. Dalton Trans. 2018, 47, 6645-6653. [CrossRef]

102. Ma, Z.N.; Liu, Z.; Wang, Z.; Ren, S.; Tang, S.; Wang, Y.P.; Xiao, S.Y.; Chen, C.; Li, W. Supplementation of American ginseng berry extract mitigated cisplatin-evoked nephrotoxicity by suppressing ROS-mediated activation of MAPK and NF-kappaB signaling pathways. Food Chem. Toxicol. 2017, 110, 62-73. [CrossRef] 
103. Mehendale, S.; Aung, H.; Wang, A.; Yin, J.J.; Wang, C.Z.; Xie, J.T.; Yuan, C.S. American ginseng berry extract and ginsenoside Re attenuate cisplatin-induced kaolin intake in rats. Cancer Chemother. Pharmacol. 2005, 56, 63-69. [CrossRef]

104. Desouky, O.; Ding, N.; Zhou, G. Targeted and non-targeted effects of ionizing radiation. J. Radiat. Res. Appl. Sci. 2015, 8, 247-254. [CrossRef]

105. Lee, T.K.; O'Brien, K.F.; Wang, W.; Sheng, C.; Wang, T.; Johnke, R.M.; Allison, R.R. American ginseng modifies Cs-induced DNA damage and oxidative stress in human lymphocytes. Open Nucl. Med. J. 2009, 1, 1-8. [CrossRef]

106. Lee, T.K.; O’Brien, K.F.; Wang, W.; Johnke, R.M.; Sheng, C.; Benhabib, S.M.; Wang, T.; Allison, R.R. Radioprotective effect of American ginseng on human lymphocytes at 90 minutes postirradiation: A study of 40 cases. J. Altern. Complement. Med. 2010, 16, 561-567. [CrossRef]

107. Wang, C.Z.; Li, X.L.; Wang, Q.F.; Mehendale, S.R.; Fishbein, A.B.; Han, A.H.; Sun, S.; Yuan, C.S. The mitochondrial pathway is involved in American ginseng-induced apoptosis of SW-480 colon cancer cells. Oncol. Rep. 2009, 21, 577-584. [CrossRef] [PubMed]

108. Bower, J.E. Cancer-related fatigue-Mechanisms, risk factors, and treatments. Nat. Rev. Clin. Oncol. 2014, 11, 597-609. [CrossRef]

109. Horneber, M.; Fischer, I.; Dimeo, F.; Rüffer, J.U.; Weis, J. Cancer-related fatigue: Epidemiology, pathogenesis, diagnosis, and treatment. Dtsch. Arztebl. Int. 2012, 109, 161-171. [CrossRef]

110. Barton, D.L.; Liu, H.; Dakhil, S.R.; Linquist, B.; Sloan, J.A.; Nichols, C.R.; McGinn, T.W.; Stella, P.J.; Seeger, G.R.; Sood, A.; Loprinzi, C.L. Wisconsin ginseng (Panax quinquefolius) to improve cancer-related fatigue: A randomized, double-blind trial, N07C2. J. Natl. Cancer Inst. 2013, 105, 1230-1238. [CrossRef]

111. Yang, C.S.; Ko, S.R.; Cho, B.G. The ginsenoside metabolite compound K, a novel agonist of glucocorticoid receptor, induces tolerance to endotoxin induced lethal shock. J. Cell. Mol. Med. 2008, 12, 1739-1753. [CrossRef]

112. Jin, Y.; Hofseth, A.B.; Cui, X. American ginseng suppresses colitis through p53-mediated apoptosis of inflammatory cells. Cancer Prev. Res. 2010, 3, 339-347. [CrossRef]

113. Kang, A.; Hao, H.; Zheng, X. Peripheral anti-inflammatory effects explain the ginsenosides paradox between poor brain distribution and antidepression efficacy. J. Neuroinflammat. 2011, 8, 100. [CrossRef]

114. Kan, J.; Velliquette, R.A.; Grann, K.; Burns, C.R.; Scholten, J.; Tian, F.; Zhang, Q.; Gui, N. A novel botanical formula prevents diabetes by improving insulin resistance. BMC Complement. Altern. Med. 2017, 17, 352. [CrossRef] [PubMed]

115. Fu, Y.; Ji, L.L. Chronic ginseng consumption attenuates age-associated oxidative stress in rats. J. Nutr. 2003, 133, 3603-3609. [CrossRef]

116. Luo, J.Z.; Luo, L. Ginseng on hyperglycemia: Effects and mechanisms. Evid. Based Complement. Alternat. Med. 2009, 6, 423-427. [CrossRef]

117. Yoo, K.M.; Lee, C.; Lo, Y.M.; Moon, B.-K. The hypoglycemic effects of American red ginseng (Panax quinquefolius L.) on a diabetic mouse model. J. Food Sci. 2012, 77, 147-152. [CrossRef]

118. Lin, E.; Wang, Y.; Mehendale, S.; Sun, S.; Wang, C.Z.; Xie, J.T.; Aung, H.H.; Yuan, C.S. Antioxidant protection by American ginseng in pancreatic beta-cells. Am. J. Chin. Med. 2008, 36, 981-988. [CrossRef]

119. Attele, A.S.; Wu, J.A.; Yuan, C.S. Ginseng pharmacology: Multiple constituents and multiple actions. Biochem. Pharmacol. 1999, 58, 1685-1693. [CrossRef]

120. Xie, J.T.; Wang, C.Z.; Ni, M.; Wu, J.A.; Mehendale, S.R.; Aung, H.H.; Foo, A.; Yuan, C.S. American ginseng berry juice intake reduces blood glucose and body weight in ob/ob mice. J. Food Sci. 2007, 72, S590-S594. [CrossRef] [PubMed]

121. Shao, Z.H.; Xie, J.T.; Vanden Hoek, T.L.; Mehendale, S.; Aung, H.; Li, C.Q.; Qin, Y.; Schumacker, P.T.; Becker, L.B.; Yuan, C.S. Antioxidant effects of American ginseng berry extract in cardiomyocytes exposed to acute oxidant stress. Biochim. Biophys. Acta 2004, 1670, 165-171. [CrossRef] [PubMed]

122. Xie, J.T.; Shao, Z.H.; Vanden Hoek, T.L.; Chang, W.T.; Li, J.; Mehendale, S.; Wang, C.Z.; Hsu, C.W.; Becker, L.B.; Yin, J.J.; et al. Antioxidant effects of ginsenoside Re in cardiomyocytes. Eur. J. Pharmacol. 2006, 532, 201-207. [CrossRef]

123. Mehendale, S.R.; Wang, C.Z.; Shao, Z.H.; Li, C.Q.; Xie, J.T.; Aung, H.H.; Yuan, C.S. Chronic pretreatment with American ginseng berry and its polyphenolic constituents attenuate oxidant stress in cardiomyocytes. Eur. J. Pharmacol. 2006, 553, 209-214. [CrossRef] 
124. Wang, J.-S.; Yin, H.-J.; Guo, C.-Y.; Huang, Y.; Xia, C.-D.; Liu, Q. Influence of high blood glucose fluctuation on endothelial function of type 2 diabetes mellitus rats and effects of Panax quinquefolius saponin of stem and leaf. Chin. J. Integr. Med. 2013, 19, 217-222. [CrossRef]

125. Sen, S.; Chen, S.; Feng, B.; Yuexiu, W.; Lui, E.M.K.; Chakrabarti, S. American ginseng (Panax quinquefolius) prevents glucose-induced oxidative stress and associated endothelial cell abnormalities. Phytomedicine 2011, 18, 1110-1117. [CrossRef]

126. Mucalo, I.; Jovanovski, E.; Rahelić, D.; Božikov, V.; Romić, Z.; Vuksan, V. Effect of American ginseng (Panax quinquefolius L.) on arterial stiffness in subjects with type-2 diabetes and concomitant hypertension. J. Ethnopharm. 2013, 150, 148-153. [CrossRef]

127. Xu, Z.; Beljan-Zdravkovic, U.; Bateman, R.M.; Jenkins, A.L.; Sievenpiper, J.L.; Stavro, M.P.; Vuksan, V. American ginseng increases plasma nitric oxide concentration in type 2 diabetes. Can. J. Diabet. Care. 2000, 24, 38.

128. Sen, S.; Chen, S.; Wu, Y.; Feng, B.; Lui, E.K.; Chakrabarti, S. Preventive effects of North American ginseng (Panax quinquefolius) on diabetic retinopathy and cardiomyopathy. Phytother. Res. 2013, 27, 290-298. [CrossRef]

129. Amin, K.A.; Awad, E.M.; Nagy, M.A. Effects of Panax quinquefolium on streptozotocin-induced diabetic rats: role of C-peptide, nitric oxide and oxidative stress. Int. J. Clin. Exp. Med. 2011, 2, 136-147.

130. Vuksan, V.; Sievenpiper, J.L.; Koo, V.Y.Y.; Francis, T.; Beljan-Zdravkovic, U.; Xu, Z.; Vidgen, E. American ginseng (Panax quinquefolius $\mathrm{L}$ ) reduces postprandial glycemia in nondiabetic subjects and subjects with type 2 diabetes mellitus. Arch. Intern. Med. 2000, 160, 1009-1013. [CrossRef]

131. Vuksan, V.; Sievenpiper, J.L.; Wong, J.; Xu, Z.; Beljan-Zdravkovic, U.; Arnason, J.T.; Assinewe, V.; Stavro, M.P.; Jenkins, A.L.; Leiter, L.A.; Francis, T. American ginseng (Panax quinquefolius L.) attenuates postprandial glycemia in a time-dependent but not dose-dependent manner in healthy individuals. Am. J. Clin. Nutr. 2001, 73, 753-758. [CrossRef]

132. De Souza, L.R.; Jenkins, A.L.; Jovanovski, E.; Rahelić, D.; Vuksan, V. Ethanol extraction preparation of American ginseng (Panax quinquefolius L.) and Korean red ginseng (Panax ginseng C.A. Meyer): Differential effects on postprandial insulinemia in healthy individuals. J. Ethnopharm. 2015, 159, 55-61. [CrossRef]

133. Mucalo, I.; Jovanovski, E.; Vuksan, V.; Dikov, V.B.; Romi, C.; Raheli, D. American ginseng extract (Panax quinquefolius L.) is safe in long-term use in type 2 diabetic patients. Evid. Based Complement. Altern. Med. 2014, 2014, 969168. [CrossRef] [PubMed]

134. Vuksan, V.; Xu, Z.Z.; Jovanovski, E.; Jenkins, A.L.; Beljan-Zdravkovic, U.; Sievenpiper, J.L.; Stavro, P.M.; Zurbau, A.; Duvnjak, L.; Li, M.Z.C. Efficacy and safety of American ginseng (Panax quinquefolius L.) extract on glycemic control and cardiovascular risk factors in individuals with type 2 diabetes: A double-blind, randomized, crossover clinical trial. Eur. J. Nutr. 2018, 58, 1237-1245. [CrossRef]

135. Jenkins, A.L.; Morgan, L.M.; Bishop, J.; Jovanovski, E.; Jenkins, D.J.A.; Vuksan, V. Co-administration of a konjac-based fibre blend and American ginseng (Panax quinquefolius L.) on glycaemic control and serum lipids in type 2 diabetes: A randomized controlled, cross-over clinical trial. Eur. J. Nutr. 2018, 57, 2217-2225. [CrossRef] [PubMed]

136. Zhang, L.; Virgous, C.; Si, H. Ginseng and obesity: Observations and understanding in cultured cells, animals and humans. J. Nutr. Biochem. 2017, 44, 1-10. [CrossRef] [PubMed]

137. Liu, W.; Zheng, Y.; Han, L.; Wang, H.; Saito, M.; Ling, M.; Kimura, Y.; Feng, Y. Saponins (ginsenosides) from stems and leaves of Panax quinquefolium prevented high-fat diet-induced obesity in mice. Phytomedicine 2008, 15, 1140-1145. [CrossRef] [PubMed]

138. Liu, R.; Zhang, J.-Z.; Liu, W.-C.; Zheng, Y.-N. Anti-obesity effects of protopanaxatriol type ginsenosides isolated from American ginseng leaves in mice fed a high-fat diet. Int. J. Biomed. Pharm. Sci. 2012, 6, 106-112. [CrossRef]

139. Yeo, C.R.; Lee, S.-M.; Popovich, D.G. Ginseng (Panax quinquefolius) Reduces cell growth, lipid acquisition and increases adiponectin expression in 3T3-L1 cells. Evid. Based Complem. Altern. Med. 2011, 2011, 610625. [CrossRef]

140. Hwang, J.T.; Lee, M.S.; Kim, H.J.; Sung, M.J.; Kim, H.Y.; Kim, M.S.; Kwon, D.Y. Antiobesity effect of ginsenoside Rg3 involves the AMPK and PPAR- $\gamma$ signal pathways. Phytotherapy Res. 2009, 23, 262-266. [CrossRef] 
141. Wu, G.Y.; Yi, J.Y.; Liu, L.; Wang, P.C.; Zhang, Z.J.; Li, Z. Pseudoginsenoside F11, a novel partial PPAR gamma agonist, promotes adiponectin oligomerization and secretion in 3T3-L1 adipocytes. PPAR Res. 2013, 2013, 701017. [CrossRef]

142. Wilson, S.A.F.; Wong, M.H.T.; Stryjecki, S.; De Boer, A.; Lui, E.M.K.; Mutch, D.M. Unraveling the adipocyte inflammomodulatory pathways activated by North American ginseng. Int. J. Obes. 2013, 3711, 350-356. [CrossRef]

143. Garbett, J.; Wilson, S.A.F.; Ralston, J.C.; De Boer, A.A.; Lui, E.M.K.; Wright, D.C.; Mutch, D.M. North American ginseng influences adipocyte macrophage crosstalk regulation of inflammatory gene expression. J. Ginseng. Res. 2016, 40, 141-150. [CrossRef]

144. Singh, R.K.; Lui, E.; Wright, D.; Taylor, A.; Bakovic, M. Alcohol extract of North American ginseng (Panax quinquefolius) reduces fatty liver, dyslipidemia, and other complications of metabolic syndrome in a mouse model. Can. J. Physiol. Pharmacol. 2017, 95, 1046-1057. [CrossRef]

145. Zhu, L.; Li, J.; Xing, N.; Han, D.; Kuang, H.; Ge, P. American ginseng regulates gene expression to protect against premature ovarian failure in rats. Biomed Res. Int. 2015, 2015, 767124. [CrossRef]

146. Fernandez-Moriano, C.; Gonzalez-Burgos, E.; Iglesias, I.; Lozano, R.; Gomez-Serranillos, M.P. Evaluation of the adaptogenic potential exerted by ginsenosides Rb1 and Rg1 against oxidative stress-mediated neurotoxicity in an in vitro neuronal model. PLoS ONE 2017, 12, e0182933. [CrossRef]

147. Murphy, L.L.; Cadena, R.S.; Chavez, D.; Ferraro, J.S. Effect of American ginseng (Panax quinquefolium) on male copulatory behavior in the rat. Physiol. Behav. 1998, 64, 445-450. [CrossRef]

148. Cai, W.; Zhang, K.; Li, P.; Zhu, L.; Xu, J.; Yang, B.; Hu, X.; Lu, Z.; Chen, J. Dysfunction of the neurovascular unit in ischemic stroke and neurodegenerative diseases: An aging effect. Ageing Res. Rev. 2017, 34, 77-87. [CrossRef]

149. Chen, Y.J.; Wallace, B.K.; Yuen, N.; Jenkins, D.P.; Wulff, H.; O’Donnell, M.E. Blood-brain barrier KCa3.1 channels: Evidence for a role in brain Na uptake and edema in ischemic stroke. Stroke 2015, 46, 237-244. [CrossRef]

150. Ohl, K.; Tenbrock, K.; Kipp, M. Oxidative stress in multiple sclerosis: Central and peripheral mode of action. Exp. Neurol. 2016, 277, 58-67. [CrossRef] [PubMed]

151. Burns, A.; Iliffe, S. Alzheimer's disease. BMJ 2009, 338, b158. [CrossRef] [PubMed]

152. Liu, X.; Erikson, C.; Brun, A. Cortical synaptic changes and gliosis in normal aging, Alzheimer's disease and frontal lobe degeneration. Dementia 1996, 7, 128-134. [CrossRef]

153. Yang, L.; Hao, J.; Zhang, J.; Xia, W.; Dong, X.; Hu, X.; Kong, F.; Cui, X. Ginsenoside Rg3 promotes beta-amyloid peptide degradation by enhancing gene expression of neprilysin. J. Pharm. Pharmacol. 2009, 61, 375-380. [CrossRef]

154. Al-Hazmi, M.A.; Rawi, S.M.; Arafa, N.M.; Wagas, A.; Montasser, A.O. The potent effects of ginseng root extract and memantine on cognitive dysfunction in male albino rats. Toxicol. Ind. Health 2015, 31, 494-509. [CrossRef]

155. Nitta, H.; Matsumoto, K.; Shimizu, M.; Ni, X.H.; Watanabe, H. Panax ginseng extract improves the performance of aged Fischer 344 rats in radial maze task but not in operant brightness discrimination task. Biol. Pharm. Bull. 1995, 18, 1286-1288. [CrossRef] [PubMed]

156. Harman, D. Aging: A theory based on free radical and radiation chemistry. J. Gerontol. 1956, 11, $298-300$. [CrossRef]

157. Jin, K. Modern biological theories of aging. Aging Dis. 2010, 1, 72-74.

158. Shi, S.; Shi, R.; Hashizume, K. American ginseng improves neurocognitive function in senescence-accelerated mice: Possible role of the upregulated insulin and choline acetyltransferase gene expression. Geriatr. Gerontol. Int. 2012, 12, 123-130. [CrossRef]

159. Sienkiewicz, M.; Głowacka, A.; Kowalczyk, E.; Kochan, E. The activity of different extracts from Panax quinquefolium L. cultures against pathogenic Staphylococcus aureus with respect to ginsenoside content. Arch. Biol. Sci. 2015, 67, 1277-1284. [CrossRef]

160. Wang, L.; Yang, X.; Yu, X.; Yao, Y.; Ren, G. Evaluation of antibacterial and anti-inflammatory activities of less polar ginsenosides produced from polar ginsenosides by heat-transformation. J. Agric. Food Chem. 2013, 61, 12274-12282. [CrossRef] 
161. Alipour, M.; Omri, A.; Suntres, Z.E. Ginseng aqueous extract attenuates the production of virulence factors, stimulates twitching and adhesion, and eradicates biofilms of Pseudomonas aeruginosa. Can. J. Physiol. Pharmacol. 2011, 89, 419-427. [CrossRef]

162. Xue, P.; Yao, Y.; Yang, X.S.; Feng, J.; Ren, G.X. Improved antimicrobial effect of ginseng extract by heat transformation. J. Ginseng Res. 2017, 41, 180-187. [CrossRef]

163. Wang, H.X.; Ng, T.B. Quinqueginsin, a novel protein with anti-human immunodeficiency virus, antifungal, ribonuclease and cell-free translation-inhibitory activities from American ginseng roots. Biochem. Biophys. Res. Commun. 2000, 269, 203-208. [CrossRef]

164. Wang, C.Z.; Du, G.J.; Zhang, Z.; Wen, X.D.; Calway, T.; Zhen, Z.; Musch, M.W.; Bissonnette, M.; Chang, E.B.; Yuan, C.S. Ginsenoside compound $\mathrm{K}$, not Rb1, possesses potential chemopreventive activities in human colorectal cancer. Int. J. Oncol. 2012, 40, 1970-1976. [CrossRef] [PubMed]

165. Kim, D.H. Gut microbiota-mediated pharmacokinetics of ginseng saponins. J. Ginseng Res. 2017, 42, $255-263$. [CrossRef]

166. Wan, J.Y.; Liu, P.; Wang, H.Y.; Qi, L.W.; Wang, C.Z.; Li, P.; Yuan, C.S. Biotransformation and metabolic profile of American ginseng saponins with human intestinal microflora by liquid chromatography quadrupole time-of-flight mass spectrometry. J. Chromatogr. A 2013, 1286, 83-92. [CrossRef]

167. Wan, J.Y.; Wang, C.Z.; Liu, Z.; Zhang, Q.H.; Musch, M.W.; Bissonnette, M.; Chang, E.B.; Li, P.; Qi, L.W.; Yuan, C.S. Determination of American ginseng saponins and their metabolites in human plasma, urine and feces samples by liquid chromatography coupled with quadrupole time-of-flight mass spectrometry. J. Chromatogr. B Analyt. Technol. Biomed. Life Sci. 2016, 1015-1016, 62-73. [CrossRef]

168. Cimo, A.; Soltani, M.; Lui, E.; Hekmat, S. Fortification of probiotic yogurt with ginseng (Panax quinquefolius) extract. J. Food Nutr. Disor. 2013, 2, 2. [CrossRef]

169. Wang, C.Z.; Yu, C.; Wen, X.D.; Chen, L.; Zhang, C.F.; Calway, T.; Qiu, Y.; Wang, Y.; Zhang, Z.; Anderson, S.; et al. American ginseng attenuates colitis-associated colon carcinogenesis in mice: Impact on gut microbiota and metabolomics. Cancer Prev. Res. 2016, 9, 803-811. [CrossRef] [PubMed]

170. Xia, J.; Zhang, Y.; Zhao, H.; Wang, J.; Gao, X.; Chen, J.; Fu, B.; Shen, Y.; Miao, F.; Zhang, J.; Teng, G. Non-Invasive monitoring of CNS MHC-I molecules in ischemic stroke mice. Theranostics 2017, 7, 2837-2848. [CrossRef]

171. Chua, Y.T.; Ang, X.L.; Zhong, X.M.; Khoo, K.S. Interaction between warfarin and Chinese herbal medicines. Singapore Med. J. 2015, 56, 11-18. [CrossRef]

172. Assinewe, V.V.; Amason, J.T.; Aubry, A.; Mullin, J.; Lemaire, I. Extractable polysaccharides of Panax quinquefolius L. (North American ginseng) root stimulate TNFalpha production by alveolar macrophages. Phytomedicine 2002, 9, 398-404. [CrossRef]

173. Yu, X.H.; Liu, Y.; Wu, X.L.; Liu, L.Z.; Fu, W.; Song, D.D. Isolation, purification, characterization and immunostimulatory activity of polysaccharides derived from American ginseng. Carbohydr. Polym. 2017, 156, 9-18. [CrossRef]

174. Lui, E.M.K.; Azike, C.G.; Guerrero-Analco, J.A.; Romeh, A.A.; Pei, P.; Kaldas, S.J.; Arnason, J.T.; Charpentier, P.A. Bioactive polysaccharides of American ginseng Panax quinquefolius L. In Modulation of Immune Function: Phytochemical and Pharmacological Characterization, The Complex World of Polysaccharides; Karunaratne, D.N., Ed.; Intech Open: London, UK, 2012; pp. 513-518.

175. Azike, C.G. American ginseng modulation of immune function and phytochemical analysis, Doctor of Philosophy, The University of Western Ontario, London, Ontario, Canada. May 2014. Available online: https://ir.lib.uwo.ca/cgi/viewcontent.cgi?article=3449\&context=etd (accessed on 26 April 2019).

176. Lü, J.M.; Yao, Q.; Chen, C. Ginseng compounds: An update on their molecular mechanisms and medical applications. Curr. Vasc. Pharmacol. 2009, 7, 293-302. [CrossRef]

177. Kim, J.H. Cardiovascular Diseases and Panax ginseng: A Review on molecular mechanisms and medical applications. J. Ginseng Res. 2012, 36, 16-26. [CrossRef]

178. Sodrul, I.M.D.; Wang, C.; Chen, X.; Du, J.; Sun, H. Role of ginsenosides in reactive oxygen species-mediated anticancer therapy. Oncotarget 2018, 9, 2931-2950. [CrossRef]

179. Kitts, D.D.; Wijewickreme, A.N.; Hu, C. Antioxidant properties of a North American ginseng extract. Mol. Cell. Biochem. 2000, 203, 1-10. [CrossRef] 
180. Chan, L.Y.; Chiu, P.Y.; Lau, T.K. An in-vitro study of ginsenoside Rb1-induced teratogenicity using a whole rat embryo culture model. Hum. Reprod. 2003, 18, 2166-3268. [CrossRef] [PubMed]

181. Liu, P.; Xu, Y.; Yin, H.; Wang, J.; Chen, K.; Li, Y. Developmental toxicity research of ginsenoside Rb1 using a whole mouse embryo culture model. Birth Defects Res. B Dev. Reprod. Toxicol. 2005, 74, 207-209. [CrossRef]

(C) 2019 by the authors. Licensee MDPI, Basel, Switzerland. This article is an open access article distributed under the terms and conditions of the Creative Commons Attribution (CC BY) license (http://creativecommons.org/licenses/by/4.0/). 